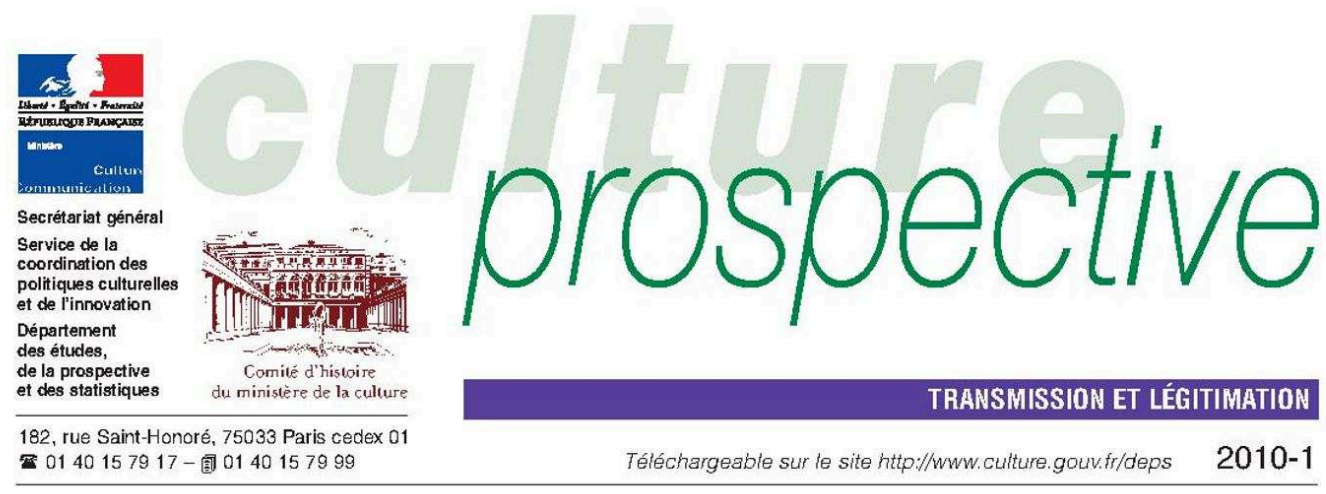

\title{
L'invention de la prospective culturelle
}

\section{Textes choisis d'Augustin Girard*}

\section{Avant-propos}

Augustin Girard m'a confié une erreur de prospective : « Ce que j'ai écrit... ne vaut que pour mon temps. » Dans son temps, il l'êtait bien plus que beaucoup, car it poursuivait celui de l'histoire à laquelle il renvoie souvent, s'inscrivait dans un présent d'action - publique - qu'il savait analyser, êvaluer, rudoyer aussi, toujours pour mieux l'encourager, l'épaulant objectivement de statistiques. Il t'a encore prolongé en dessinant des visages aux futurs possibles de la culture et de ses potitiques.

Quelques-uns des textes qu'il a semés, ici rassemblés, portent toujours des bourgeons, tandis que d'autres mûrissent encore et que quelques-uns fleurissent ou déjà refleurissent. Dans cette cueillette qui fait recueil, le lecteur trouvera done bien moins de quoi faire rétros. pective que prospective. Ces textes donnent la liberté de trouver les racines encore fécondes de l'invention de la prospective culturelle. Celle-ci se nourrit de la détection de tendances, de l'invention de méthodes, du regard sans complaisance sur les politiques publiques et de leur évaluation, et plus encore de la libre réflexion que ces enjeux suscitent.

Sous ses quelques aspects, le singulier mélange d'un esprit critique, d'un esprit de liberté et, peut-être plus encore, $d$ 'un esprit de jeu se trame dans ces textes. Il nous invite à pour. suivre les réflexions qu'il a ouvertes et que le présent agite de nouveau et sans doute autrement:

- peut-on résoudre la tension entre la culture et les loisirs qui tendent à la désacraliser, sans tenir compte de la réalité et de la fécondité des «subcultures"?

- peut-on se satisfaire des stratégies d'offres, fussent-elles rationnelles, si les forces de la demande sociale sont plus puissantes, variées, complexes et parfois plus mobiles?

- que vaut objectivement le nombre des « contacts» aux ceuvres facilités par l'émergence et la domination des «machines culturelles» si les outils et méthodes pour les appréhender font encore défaut?

- qu'y a-t-il de vraiment neuf dans la structure économique des industries culturelles contemporaines confrontées à des goulets d'étranglement, à la répétition des stratégies de star system ?

- quelle « autodidaxie » faut-il encore imaginer au temps du numérique dont la grammaire et le vocabulaire continuent de s'inventer?

- que faire de l'accélération, du rétrécissement et de l'émiettement de l'espace-temps que produisent les communications de toutes sortes?

- etc.

Parmi beaucoup d'autres, ces quelques questions soulevées par Augustin Girard au cours des dernières décennies $d u X X^{e}$ siècle resurgissent avec une acuité toute particulière pour analyser l'actuelle révolution numérique, en détecter les futurs enjeux, renouveler les moyens d'envisager ses futurs effets, imaginer les politiques culturelles les plus pertinentes. À tous ces titres - comme à ceux que le lecteur saura trouver-, lire ou relire ces textes, restitués dans leurs temps, est précieux.

\begin{tabular}{|c|c|}
\hline SOMMAIRE & \\
\hline lu Présent & \\
\hline $\begin{array}{l}\text { Pourquoi des recherches? } \\
\text { La fin de l'ère des goûts } \\
\text { et des couleurs .............. }\end{array}$ & \\
\hline $\begin{array}{l}\text { Développement culturel } \\
\text { et politique culturelle } \ldots\end{array}$ & \\
\hline $\begin{array}{l}\text { Pour une politique } \\
\text { de la lecture .... }\end{array}$ & 10 \\
\hline $\begin{array}{l}\text { Pour une nouvelle stratégie } \\
\text { de la culture }\end{array}$ & 12 \\
\hline $\begin{array}{l}\text { Prospective du } \\
\text { développement } \\
\text { culturel ........ }\end{array}$ & 14 \\
\hline Industries culturelles ...... & 15 \\
\hline Pratiques et politiques ..... & 19 \\
\hline L'enjeu culturel . . & 21 \\
\hline Trente ans après. & 24 \\
\hline $\begin{array}{l}\text { Une dynamique } \\
\text { pour l'avenir. }\end{array}$ & \\
\hline $\begin{array}{l}\text { Un cas de partenariat } \\
\text { entre administration } \\
\text { et recherche scientifique : } \\
\text { la socio-économie } \\
\text { de la culture .................. }\end{array}$ & \\
\hline $\begin{array}{l}\text { La naissance des politiques } \\
\text { culturelles et les } \\
\text { Rencontres d'Avignon } \\
(1964-1970)\end{array}$ & \\
\hline Repères chronologiques. & 32 \\
\hline
\end{tabular}

*Augustin Girard (1926-2009). Chef du Service des études et recherches, devenu Département des études, de la prospective et des statistiques (1963-1993), puis président du Comité d’histoire du ministère de la Culture (1993-2007). 


\section{L'invention de la prospective culturelle}

Textes choisis d'Augustin Girard

\section{Augustin Girard}

Éditeur : Département des études, de la prospective et des statistiques

Lieu d'édition : Paris

Année d'édition : 2010

Date de mise en ligne : 21 septembre 2015

Collection : Culture prospective

ISBN électronique : 9782111398122

\section{Drentation ebooks}

http://books.openedition.org

Édition imprimée

Date de publication : 1 janvier 2010

Référence électronique

GIRARD, Augustin. L'invention de la prospective culturelle : Textes choisis d'Augustin Girard. Nouvelle édition [en ligne]. Paris : Département des études, de la prospective et des statistiques, 2010 (généré le 25 avril 2021). Disponible sur Internet : <http://books.openedition.org/deps/381>. ISBN :

9782111398122

(c) Département des études, de la prospective et des statistiques, 2010

Creative Commons - Attribution - Pas d'Utilisation Commerciale 3.0 non transposé - CC BY-NC 3.0 


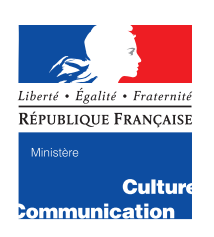

Secrétariat général

Service de la coordination des politiques culturelles et de l'innovation Département des études, de la prospective et des statistiques
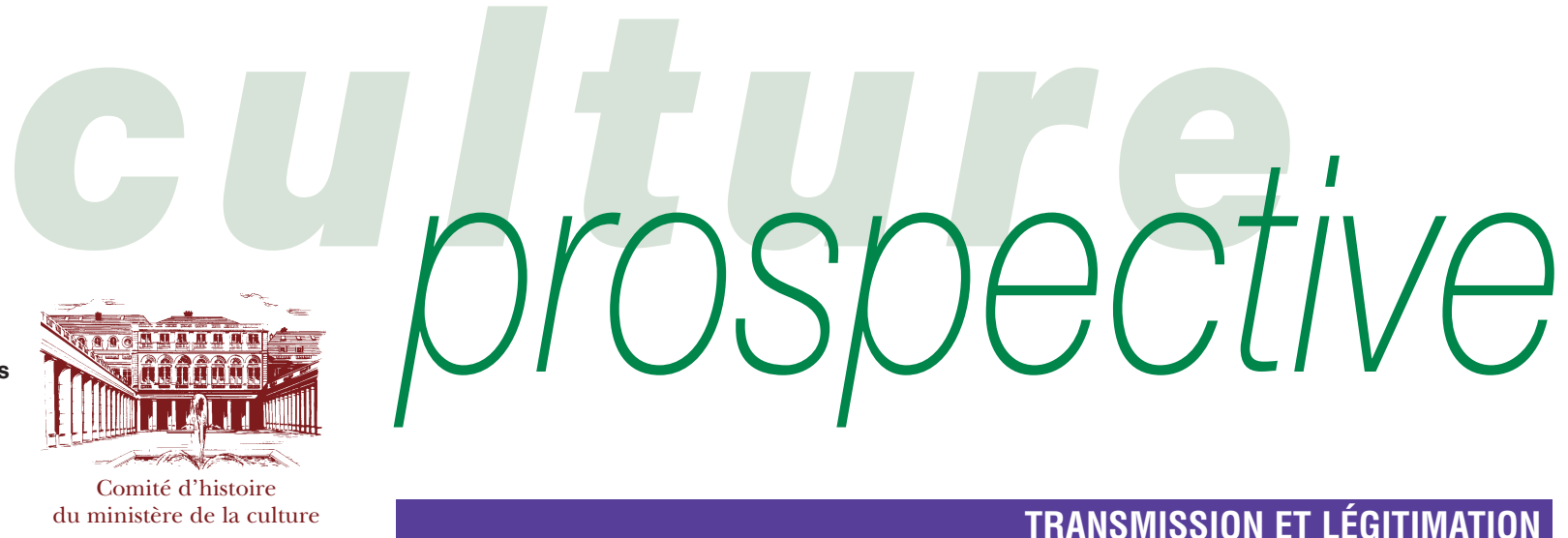

\section{L'invention de la prospective culturelle}

\section{Textes choisis d'Augustin Girard*}

\section{Avant-propos}

Augustin Girard m'a confié une erreur de prospective : «Ce que j’ai écrit... ne vaut que pour mon temps. » Dans son temps, il l'était bien plus que beaucoup, car il poursuivait celui de l'histoire à laquelle il renvoie souvent, s'inscrivait dans un présent d'action - publique - qu'il savait analyser, évaluer, rudoyer aussi, toujours pour mieux l'encourager, l'épaulant objectivement de statistiques. Il l'a encore prolongé en dessinant des visages aux futurs possibles de la culture et de ses politiques.

Quelques-uns des textes qu'il a semés, ici rassemblés, portent toujours des bourgeons, tandis que d'autres mûrissent encore et que quelques-uns fleurissent ou déjà refleurissent. Dans cette cueillette qui fait recueil, le lecteur trouvera donc bien moins de quoi faire rétrospective que prospective. Ces textes donnent la liberté de trouver les racines encore fécondes de l'invention de la prospective culturelle. Celle-ci se nourrit de la détection de tendances, de l'invention de méthodes, du regard sans complaisance sur les politiques publiques et de leur évaluation, et plus encore de la libre réflexion que ces enjeux suscitent.

Sous ses quelques aspects, le singulier mélange d'un esprit critique, d'un esprit de liberté et, peut-être plus encore, d'un esprit de jeu se trame dans ces textes. Il nous invite à poursuivre les réflexions qu'il a ouvertes et que le présent agite de nouveau et sans doute autrement :

- peut-on résoudre la tension entre la culture et les loisirs qui tendent à la désacraliser, sans tenir compte de la réalité et de la fécondité des «subcultures »?

- peut-on se satisfaire des stratégies d'offres, fussent-elles rationnelles, si les forces de la demande sociale sont plus puissantes, variées, complexes et parfois plus mobiles?

- que vaut objectivement le nombre des «contacts» aux aeuvres facilités par l'émergence et la domination des «machines culturelles » si les outils et méthodes pour les appréhender font encore défaut?

- qu'y a-t-il de vraiment neuf dans la structure économique des industries culturelles contemporaines confrontées à des goulets d'étranglement, à la répétition des stratégies de star system?

- quelle «autodidaxie » faut-il encore imaginer au temps du numérique dont la grammaire et le vocabulaire continuent de s'inventer?

- que faire de l'accélération, du rétrécissement et de l'émiettement de l'espace-temps que produisent les communications de toutes sortes?

- etc.

Parmi beaucoup d'autres, ces quelques questions soulevées par Augustin Girard au cours des dernières décennies $d u X^{e}$ siècle resurgissent avec une acuité toute particulière pour analyser l'actuelle révolution numérique, en détecter les futurs enjeux, renouveler les moyens d'envisager ses futurs effets, imaginer les politiques culturelles les plus pertinentes. À tous ces titres - comme à ceux que le lecteur saura trouver-, lire ou relire ces textes, restitués dans leurs temps, est précieux.

Philippe Chantepie

\section{SOMMAIRE}

Les tâches du Présent

Pourquoi des recherches? La fin de l'ère des goûts et des couleurs

Développement culturel et politique culturelle

Pour une politique de la lecture

Pour une nouvelle stratégie de la culture

Prospective du développement culturel

Industries culturelles

Pratiques et politiques ......

L'enjeu culturel .

Trente ans après

Une dynamique pour l'avenir

Un cas de partenariat entre administration et recherche scientifique : la socio-économie de la culture

La naissance des politiques culturelles et les

Rencontres d'Avignon (1964-1970)

Repères chronologiques

*Augustin Girard (1926-2009). Chef du Service des études et recherches, devenu Département des études, de la prospective et des statistiques (1963-1993), puis président du Comité d'histoire du ministère de la Culture (1993-2007). 


\section{Les tâches du Présent}

1965 : Augustin Girard, à l'invitation de Bernard Anthonioz, a rejoint le ministère des Affaires culturelles d'André Malraux. Il s'exprime comme ancien rapporteur - en 1961 - du groupe de travail «Action culturelle » à la Commission du patrimoine artistique et de l'équipement culturel du IV Plan* et comme animateur d'un groupe d'étude des loisirs à l'Institut d'aménagement et d'urbanisme de la région parisienne.

\section{UNE DIMENSION NOUVELLE}

\section{DE LA VIE DE LA SOCIÉTÉ}

Les loisirs des plus larges couches de la population constituent dans une société hautement développée et très urbanisée une part de plus en plus importante de l'activité économique, un moteur puissant pour le développement social en même temps qu'un élément majeur dans l'équilibre de la vie des hommes. Tous ceux qui ont à prendre des décisions sur l'équipement des collectivités en sont depuis quelques années profondément conscients [...] À tous il apparaît que la qualité de la civilisation de demain sera largement commandée par le contenu du loisir des masses.

En effet, l'évolution des modes de vie dans la société à haut niveau de consommation agit directement sur les loisirs : l'accroissement de l'instruction, du pouvoir d'achat, des déplacements, des moyens de diffusion, du rythme et de la durée de la vie, en même temps que l'extension et la transformation radicale des temps de loisirs dans l'année, dans la semaine ou dans la journée ont déjà amené et vont entraîner dans les années qui viennent une véritable mutation des besoins ressentis par la population dans le domaine des loisirs et de la vie culturelle.

Or, devant cette « explosion » des besoins, la France ne dispose actuellement d'aucun organisme de réflexion, d'étude ou de décision [...] L'étude des besoins de loisirs et des possibilités de vie culturelle des différentes catégories de population est depuis peu une ambition réalisable : il y a là un immense «marché » que les sciences humaines sont en mesure d'étudier objectivement $[\ldots]$.

\section{L'ÉVALUATION DES BESOINS}

[...] On assiste depuis quelques années à une puissante montée des besoins dans le domaine des loisirs. Et lorsque l'on se demande si ce mouvement se poursuivra, on s'aperçoit alors qu'il n'est qu'à ses débuts [et on peut] penser que le doublement de la demande observé entre 1950 et 1962 redoublera pour 1970, et encore une fois pour 1985 [...] Telle est la quantité de la demande, l'ampleur du phénomène. Mais quelle est sa nature ? Que sont les loisirs ?* Comment sont-ils vécus par chacune des catégories de la population?

\section{L'ENQUÊTE AUPRÈS DU PUBLIC}

[...] La réponse doit être cherchée, non dans l'appréciation subjective, mais dans l'observation scientifique et objective : l'enquête par sondage auprès du public. [Toutefois,] l'évaluation ainsi faite ne constitue pas, à proprement parler, une prévision, ni une demande réelle; elle n'a pas de valeur objective et ne saurait être prise à la lettre. Elle permet simplement de prendre conscience de l'ampleur des phénomènes à attendre ainsi que des conditions les plus apparentes de la demande future. De plus, simple extrapolation, elle doit être complétée [...] par cinq autres [modalités] d'évaluation des besoins.

La première est l'enquête auprès des experts, des fonctionnaires spécialisés (inspecteurs régionaux de la jeunesse, du tourisme, etc.) et des élus locaux.

\section{L'« ardente obligation » du Plan}

Dès 1959, André Malraux et ses collaborateurs prennent conscience que le nouveau ministère des Affaires culturelles se devait d'apporter sa contribution aux travaux du Plan : non seulement pour des raisons fondamentales, compte tenu des enjeux liés à la culture dans la société à venir ; mais aussi parce que sa participation active permettrait d'ancrer durablement la nouvelle politique culturelle dans l'action gouvernementale et d'augmenter les moyens mis à sa disposition. Un groupe de travail est constitué, chargé d'étudier les divers problèmes d'équipements culturels dans la région de Paris, dont le rapporteur est Augustin Girard.

Le IVe Plan a marqué une phase exemplaire de l'histoire de la planification française, pour plusieurs raisons : la personnalité du nouveau commissaire général du Plan, Pierre Massé; la conjoncture des années 1960-1962 et la régularité de la croissance mondiale; l'attachement du général de Gaulle à l'«ardente obligation» de la planification. Ce plan s'articulait autour de trois objectifs: une croissance forte dans le respect des grands équilibres; une progression des équipements collectifs deux fois plus rapide que celle du PIB; un effort de correction des inégalités sociales et régionales, avec une attention particulière aux problèmes de répartition des fruits de l'expansion. Le IVe Plan a été le mieux exécuté de tous les Plans. 


\section{La « civilisation du loisir »}

Les années 1960 correspondent en France à l'apogée des "Trente Glorieuses », ces trois décennies ayant suivi la Libération et que caractérisent une croissance soutenue, la satisfaction de plus en plus grande des besoins fondamentaux et l'augmentation du niveau de vie. Dans un tel contexte, la question de l'occupation du temps libre devient essentielle et amène certains chercheurs à pronostiquer l'avènement de la « civilisation du loisir ». Associés aux travaux du Plan, ces derniers en viennent à élaborer la notion de "développement culturel », qui inspirera pour une bonne part la politique culturelle de la décennie suivante, notamment lors du passage de Jacques Duhamel rue de Valois (1971-1973). Parmi ces chercheurs figure Joffre Dumazedier (1915-2002). Sociologue et chercheur au CNRS, il est un des pionniers, en France, des études sur les loisirs et la culture populaire. Avec des amis appartenant tous à la génération du « Front populaire " - Bénigno Cacérès, Paul Lengrand, Joseph Rovan... -, il fonde en 1944 le mouvement d'éducation populaire "Peuple et Culture », qui défend le droit à l'éducation et à la culture pour tous et tout au long de la vie. Adepte d'une sociologie engagée, il intervient lui-même sur certains terrains, notamment à Annecy et à Grenoble. II publie en 1962 un ouvrage pionnier - Vers la civilisation du loisir -, étude sur le loisir des masses et les interactions avec l'ensemble des activités de la vie quotidienne, que ce soit le travail, la famille ou la politique.

Ceux-ci en savent souvent plus long que le plus habile sociologue après une vaste enquête. Leur concours est indispensable.

Plus tournée vers l'avenir est la deuxième sorte d'enquête, qui doit être menée auprès des «leaders d'opinion », dirigeants et militants des associations qui œuvrent dans le domaine.

Plus profonde est l'enquête qualitative, qui est menée par interviews non directives auprès de quelques échantillons typiques de la population: on en obtiendra les tendances qui cherchent à se satisfaire à long terme.

Très efficaces, les comparaisons internationales, qui permettent de discerner les niveaux de loisirs auxquels correspondent divers seuils atteints dans les niveaux de vie, fournissent également des hypothèses d'évolution des besoins.

Enfin, la démarche prospective, qui consiste à imaginer quelles sont les principales données de la vie économique et sociale du pays à un « horizon » donné, conduit à diverses propositions pour une politique des loisirs. Le but de la démarche prospective n'est pas de dresser un tableau cohérent de la société " vingt ans après », ce qui est impossible, mais de retenir ce qui paraît commun à toutes les hypothèses possibles. Ces composantes communes permettent alors de tirer trois ordres de conclusions : quelles sont les lignes de force les plus probables de l'évolution future; quelles sont les dispositions à prendre avant même le développement des phénomènes (par exemple : réserver des terrains, former des formateurs, créer un outil scientifique d'observation des phénomènes); quels sont les éléments du présent sur lesquels doit se fonder la politique de développement.

Les six méthodes se compensent pour atténuer le caractère mécanique de l'extrapolation. Elles permettent de prendre en considération les tendances nouvelles qui commencent à se faire jour et qui sont perçues par les « relais » locaux. Elles introduisent enfin dans la prévision des préoccupations normatives qui sont inévitables et indispensables.

Il reste évident en effet qu'on ne saurait passer directement de l'information à la décision et que ce sont les systèmes de valeur qui doivent commander la définition des objectifs et présider à la préparation des décisions.

\section{L'ÉTABLISSEMENT D'UNE POLITIQUE}

Les prévisions ne font pas une politique: en planification, le stade de la prévision ne sert qu'à préparer le stade suivant, qui est celui des objectifs. Si l'étape de la prévision, qui relève des techniciens, est celle de la quantité, l'étape des objectifs peut être celle de la qualité - et elle est l'affaire de la nation. Aussi les chiffres et les méthodes un peu arides ne [visentils] qu'à souligner l'importance de la question posée à la nation. Le point essentiel est de savoir quelle réponse la nation veut lui donner.

À une question ainsi posée, la réponse pourra paraître simple à beaucoup : c'est à la puissance publique de fournir une offre de qualité. Hélas ! Cette réponse est économiquement et politiquement fort peu viable [...] Faut-il dès lors en conclure que le loisir doit être entièrement laissé aux jeux du marché, aux entrepreneurs, aux commerçants ? Ce don nouveau de la société industrielle, chance unique pour le développement de la personne et de la communauté, serat-il gaspillé en satisfactions futiles, pour le plus grand profit des marchands? Arrivera-t-on au « chaos des loisirs » que certains dénoncent déjà ? Il y a là une demande immense qui est comme un défi aux gouvernants $[\ldots]$

Ces propositions pour une politique des loisirs paraîtront bien précises et concrètes pour un problème qui n'est pas « mûr ». Mais est-il vraiment nécessaire d'attendre que les fruits soient blets pour qu' on songe à les cueillir?

Source: Janus. L'Homme, son Histoire et son Avenir, n 7, juin-août 1965, «La révolution du loisir », 159 p. Ont participé à ce numéro Patrice Boussel, Maurice Clavel, Jean Fourastié, Georges Friedmann, Augustin Girard, Jean-François Gravier, Maurice Herzog, Paul Lafargue, Morvan Lebesque, Madeleine Léo-Lagrange, Daniel Mayer, André Parinaud, Jacques Peuchmaurd, Évelyne Sullerot et alii. Éditeurs : Nouvelle Librairie de France et Robert Laffont. 


\section{Pourquoi des recherches?}

\section{La fin de l'ère des goûts et des couleurs}

C'est en qualité de "chargé des études au ministère des Affaires culturelles » qu'Augustin Girard signe ce texte paru au sein d'un dossier intitulé Des chiffres pour la culture. Colloque de Bourges, dans la revue trimestrielle de l'Association d'étude pour l'expansion de la recherche scientifique. Créée à l'instigation de Pierre Mendès France, cette structure, composée de chercheurs, industriels, scientifiques et syndicalistes, entendait incarner la volonté du gouvernement de mettre en place une politique active de la recherche.

Recourir à la recherche scientifique pour préciser une politique de développement culturel est une entreprise qui paraît se situer à mi-chemin entre la plaisanterie et le sacrilège. Voilà bien nos technocrates « saisis » par la statistique et les sondages, envoûtés par les chiffres jusqu'à vouloir maintenant mathématiser les «mystères sacrés de l'art »... Halte-là ! Halte à la mode et gare à l'imposture! Que la culture, au moins, reste le dernier refuge de l'homme! Mais le recours à la science - aux sciences sociales essentiellement est commandé par les faits.

Il est devenu banal d'observer que l'évolution des modes de vie agit directement dans le domaine culturel: l'accroissement de l'instruction, du pouvoir d'achat, des déplacements, des moyens de diffusion, en même temps que la transformation des temps de loisirs dans l'année ou dans la semaine, entraîne une véritable «mutation» des besoins ressentis par la population dans le domaine des loisirs et de la vie culturelle.

De 1950 à 1962, les achats de disques ne se sont pas multipliés par deux mais par dix. De même, les Français achètent sept fois plus d'appareils de photographie ou de cinéma qu'en 1950. Le poste «loisirs et culture » est celui qui s'accroît le plus vite de tous les postes du budget des ménages, avant l'automobile, le logement ou la santé.

\section{LA MUTATION CULTURELLE}

Cet accroissement de la demande de biens culturels est sans précédent. Or, pour y répondre, les pouvoirs publics disposent en 1964 d'institutions et de méthodes de gestion qui sont celles du XIX ${ }^{\mathrm{e}}$ siècle.
La culture et l'emploi du loisir étaient alors le domaine exclusif des privilégiés et de quelques groupes bénévoles : l'œuvre de la République fut seulement de gérer - petitement - l'héritage reçu des monarques, des princes et des évêques. L'État et les collectivités locales ont tenté de succéder à ceux-ci dans leur rôle de mécènes, de constructeurs ou de collectionneurs. Quant à la diffusion culturelle, ils se bornèrent à accorder une aide fragmentée et non coordonnée à quelques initiatives passagères. Or, pendant ces quatre-vingtdix ans, la scolarité devenait obligatoire, le pouvoir d'achat doublait ainsi que le temps libre, la radio et la télévision pénétraient dans des millions de foyers : aujourd'hui, les pouvoirs publics ne peuvent plus échapper à l'obligation d'offrir aux adultes comme aux jeunes des équipements permanents, des animateurs professionnels, et ils ne peuvent le faire que dans le cadre de politiques à long terme, cohérentes avec les grandes options économiques et sociales d'aménagement de la nation.

Ainsi, à la «mutation» de la demande doit donc répondre une «mutation» de la politique culturelle : - la crise que connaissent les véhicules traditionnels de la culture - théâtres, orchestres, cinéma -, en même temps qu'elle témoigne des transformations profondes des modes de vie, appelle des remèdes d'une espèce nouvelle ;

- il ne s'agit plus de faire progresser peu à peu le montant des crédits culturels, mais de leur faire faire un bond - celui-là même qui est constaté dans la demande privée pour le même secteur (non pas l'indice 150 mais 500);

- la nature même de l'intervention publique doit être repensée. La puissance publique ne peut plus se borner à contrôler, à gérer, à équilibrer : devant l'ampleur nouvelle de la demande et à côté des réponses anarchiques des marchands, l'État ne peut pas ne pas se faire initiateur, animateur, organisateur. 
UNE NÉCESSITÉ NOUVELLE :

\section{LA RECHERCHE}

C'est de cette mutation que prirent conscience les membres de la Commission de l'équipement culturel lorsqu'ils furent appelés en 1961 à définir pour la première fois un chapitre culturel dans le Plan économique et social de la nation. Mais en même temps, ils s'apercevaient que l'ampleur des phénomènes culturels, le rythme de leur développement, leur nouveauté surtout ne permettaient plus qu'on définît des politiques par le seul recours à l'expérience et au passé. Tenus de situer le développement culturel dans le développement économique et social, ils avaient besoin de données [...], de chiffres : il n'y en avait pas. Ils inscrivirent donc au $\mathrm{IV}^{\mathrm{e}}$ Plan des programmes d'études descriptives : inventaire des équipements et des animateurs, statistiques de fréquentation, des coûts des investissements et des fonctionnements.

Ainsi seulement pourront être établies des comparaisons avec le passé ou avec l'étranger qui permettront de faire « le point» de la culture en France, ainsi que des «comptes culturels » qui situeront l'activité culturelle de la nation parmi les autres secteurs de l'économie et de la vie sociale. Enfin les besoins culturels de l'ensemble de la population pourront être inscrits à leur place dans la grande montée des besoins sociaux et ne plus être négligés comme domaine du superflu et de la fantaisie individuelle.

En même temps, puisque ce développement doit atteindre tous les milieux sociaux, il devient nécessaire d'étudier pourquoi la culture ne «passe pas» puis comment, par quels moyens nouveaux, elle pourrait « passer » jusqu'à eux. Des études profondes, relevant de la psychologie et de la sociologie, doivent permettre de déceler les besoins latents, de saisir les motivations cachées derrière les comportements. Ainsi pourra-t-on déterminer les meilleurs lieux d'application des investissements futurs, la nature, la taille et la localisation des équipements. L'étude, par exemple, du public - et du non-public - des musées permet de mieux déterminer les obstacles qui empêchent l'immense majorité des Français de connaître et d'apprécier leur patrimoine. De même, une étude à la fois économique et psycho-sociologique du théâtre permet de cerner les causes et les limites du malaise qui le frappe. De même encore, une étude approfondie de la fréquentation des cinémas permet de savoir où il convient de porter l'effort pour remédier à la crise.

Enfin, puisque les moyens de diffusion et les modes de vie subissent une mutation, il est indispensable de lancer des expériences, de les suivre de près et d'en tirer des conclusions pour les programmes à venir. Les trois maisons de la culture existantes ont ainsi été étudiées dans leur rayonnement auprès de la population à laquelle elles s'adressent. De même, l'incidence de la télévision sur la vie culturelle des Français a fait l'objet d'une étude spéciale.

Un tel programme d'études est, à notre connaissance, unique au monde : certes, les sociologues américains ont mené les recherches les plus remarquables sur les communications, notamment par les moyens audiovisuels, mais c'était en vue d'applications commerciales. En Scandinavie, en Allemagne, les universités populaires étudient certains problèmes pédagogiques limités. Mais la notion d'un programme d'ensemble destiné à aider la puissance publique à définir une politique est une notion nouvelle. Ses conséquences sont considérables.

\section{Recherche scientifique et aide à la décision}

Augustin Girard ne doute pas, quand il écrit ce texte, que les résultats des recherches qu'il préconise soient avant tout destinés aux responsables politiques et administratifs de la politique culturelle de l'État. Mais, trente ans plus tard, il fera l'observation suivante: "Si l'on prend du recul par rapport aux deux cents publications du Département, on s'aperçoit qu'elles ont informé au sens fort, c'est-à-dire proposé des concepts organisateurs, des chiffres, des états des lieux, des évaluations à un milieu bigarré et osmotique de deux à trois milliers d'acteurs du domaine culturel - dirigeants professionnels et associatifs, administrateurs et élus locaux (plus encore que nationaux), enseignants, chercheurs et militants -, plutôt que provoqué, dans le délai minimum, des stratégies nouvelles dans les directions concernées. On touche là à un problème structurel, qui n'est pas propre au ministère de la Culture, ni même à la haute administration dans son ensemble et a fortiori à la sphère politique. Il y a paradoxalement comme une antinomie entre l'aide à la décision et la décision » (cf. p. 24).

\section{UNE ATTITUDE NOUVELLE : L'OBJECTIVITÉ SCIENTIFIQUE}

Une telle campagne de recherches commence à fournir dès la fin de 1964 une moisson considérable de faits et de réflexions. Mais plus importante, peutêtre, est l'attitude radicalement nouvelle qu'elle introduit dans les décisions culturelles.

D'abord, elle oblige à saisir la culture telle qu'elle est vécue par la population totale, et non plus par l'élite « cultivée ». Il apparaît alors que l'on ne peut pas traiter les problèmes d'équipement culturel sans les situer d'une part, par rapport aux moyens de communication de masse, et d'autre part, par rapport à la vie de loisir des Français. Les loisirs ne sont pas la culture, ils ne sont pas porteurs de valeur, ils sont dangereusement ambigus, mais ils sont le moyen de la culture et ils constituent son cadre. Il ne suffit plus d'être passionné de théâtre pour être capable de définir une politique d'accès aux œuvres dramatiques pour un public qui s'étend à la nation tout entière. Le problème des lieux, des moments et des programmes ne peut se traiter que compte tenu des modes de loisirs des individus. 


\section{UN OUTIL NOUVEAU : LE CHIFFRE}

Objectivement, la vie culturelle des individus apparaît ainsi comme une consommation parmi d'autres, dans une société qui est dominée par la consommation. La « consommation culturelle » est en compétition avec les autres, et celui qui offre des biens culturels - représentations théâtrales, films ou concerts doit savoir dans quelles conditions il engage la compétition avec celui qui offre des automobiles ou des sports d'hiver.

Cette compétition se traduisant par des chiffres, il est nécessaire - et il devient possible - de «quantifier » le domaine culturel. Ce que l'on chiffre, ce n'est pas la culture, mais les moyens de la culture. Or, cette opération, qui paraît barbare à beaucoup et comme anti-culturelle dans son essence, se révèle la plus profitable qui soit pour la culture : en effet, dès que des statistiques sont établies - il n'y avait pas de statistiques culturelles* jusqu'à maintenant - des comparaisons peuvent être faites, soit dans le temps, à l'intérieur d'un même pays, soit de pays à pays. De ces comparaisons on peut tirer des normes, et de cellesci des critères d'intervention pour la puissance publique. Une certaine objectivité peut enfin s'introduire dans le domaine culturel.

Ainsi, par exemple, lorsqu'un groupe d'amis du théâtre demandait au maire d'une ville d'en construire un, il n'avait pour persuader le conseil municipal que la force de sa rhétorique et peut-être quelques arguments électoraux. Avec des chiffres, au contraire, il

\section{Les enquêtes du Service des études et recherches du ministère de la Culture}

\section{Enquête sur les dépenses culturelles des collectivités territoriales}

Dans les années 1970, le SER entreprend de réaliser des enquêtes sur le financement public de la culture au niveau des financeurs nationaux et territoriaux - administrations de l'État (ministère de la Culture et autres ministères) puis établissements publics régionaux, enfin départements et communes.

\section{Enquête sur les pratiques culturelles des Français}

Réalisée pour la première fois en 1973, cette enquête a été renouvelée à quatre reprises - 1981, 1989, 1997, 2008 - avec la préoccupation première d'assurer les conditions d'une comparabilité rigoureuse entre les résultats des cinq éditions. Cette contrainte est illustrée par deux exigences fondamentales:

- l'enquête par sondage porte toujours sur la même population de référence - la population résidant en France, âgée de quinze ans et plus;

- une grande partie du questionnaire initial a été conservée en l'état, même si plusieurs innovations ont été apportées au fil du temps pour tenir compte des mutations intervenues. L'objectif fixé dès le départ était d'«évaluer le poids respectif de toutes les pratiques d'ordre culturel et socioculturel mais aussi mettre en évidence les articulations qui existent entre elles, leurs complémentarités et leurs oppositions" (extrait de l'avant-propos, Enquête 1973). peut montrer ce qui se fait à Leicester, à Malmö ou à Ljubljana, et quel est le niveau de dépenses culturelles normal pour une ville comme la sienne. Le chiffre n'est donc pas sacrilège pour l'action culturelle : il est un de ses outils.

\section{DES CONCEPTS NOUVEAUX : ÉCONOMIQUES}

L'obligation de traiter les questions culturelles comme des problèmes économiques et sociaux a un autre avantage : elle conduit à dégager des concepts nouveaux qui permettent de traiter de sujets qui sont obscurcis par la passion légitime que soulèvent les valeurs culturelles. Si par exemple on applique à la musique les notions économiques d'offre et de demande, on apprend que les besoins musicaux des Français sont mieux satisfaits en 1964 que jamais auparavant, en quantité comme en qualité. Cependant, on mesure que l'immense majorité des heures d'écoute musicale est assurée par la télédiffusion et le disque, secteur qui n'emploie que quelque quatre cents musiciens. Or, il y a cinquante ans, la diffusion musicale était assurée par huit mille professionnels au moins. L'INSEE en recense le même nombre actuellement, mais la plupart de ces musiciens sont réduits à exercer des emplois qui ne correspondent pas à leur vocation. Le chiffre permet de voir que ce ne sont pas des subventions ici ou là qui apporteront un remède, mais une politique d'ensemble orientant notamment les jeunes vers d'autres carrières musicales. La réflexion est partie non d'une valeur esthétique, qui est en effet sacrée, mais de données sur l'emploi et sur la technique, sur lesquelles on peut raisonner.

Un sociologue américain a montré que les fonctions successives d'un musée étaient: la collecte, la conservation, la présentation et enfin la diffusion. Ces concepts permettent de dégager les critères d'une programmation qui serait impossible si l'on ne considérait que les œuvres elles-mêmes.

Mais de tels critères peuvent être étendus à l'ensemble de l'action culturelle, et l'on peut alors y reconnaître cinq fonctions essentielles: la création, la conservation, la diffusion, la formation et la recherche. Cette répartition en fonctions permet à son tour de mieux pondérer les grands choix auxquels oblige la planification. Ici encore, la réflexion n'est pas partie de l'objet d'art, mais de la société par rapport à laquelle on a cherché à définir la fonction de l'objet d'art.

\section{LA DÉMARCHE MÊME}

\section{DE LA PLANIFICATION}

Cette démarche, qui consiste à partir de la population, de ses modes de vie et de ses besoins, à les exprimer en chiffres, en termes économiques et en programmes, c'est celle même de la planification. 
Lorsqu'il s'agit de définir un niveau d'activité pour l'entreprise comme pour la nation, la démarche planificatrice, surtout à partir du $\mathrm{IV}^{\mathrm{e}} \mathrm{Plan}$, consiste à partir non plus de la production, comme on faisait autrefois, mais du consommateur et de sa demande.

Le renversement ainsi opéré dans la gestion de l'entreprise ou de l'État peut se retrouver dans le domaine culturel. On considérera alors qu'il faut se préoccuper non seulement de l'offre de culture, mais aussi de la demande des publics. Certes, il ne suffit pas de répondre à la demande du public pour définir une action culturelle, mais il faut que l'offre parte de cette demande, la dépasse, la précède, mais ne la perde jamais. Suffit-il, pour dire qu'une exposition est un succès, de rassembler savamment des toiles encore jamais réunies, ou faut-il encore qu'un très large public en ait été informé, qu'il ait pu venir, et qu'il ait été rendu capable d'admirer?

\section{RENVERSEMENT}

On s'aperçoit alors que ce qui est renversement dans l'ordre économique est révolution en politique culturelle : jusqu'à maintenant, la décision de «favoriser les Beaux-Arts » était prise «d'en haut » par un esprit distingué ou généreux. Il s'agissait d'ailleurs du domaine du superflu : la culture était le luxe et l'ornement d'un individu. Aujourd'hui, la culture est considérée comme un «besoin » de l'individu. Dès lors, ce besoin s'inscrit dans la montée des besoins sociaux : le développement culturel prend sa place dans le développement social de la nation à côté du développement de l'instruction dont il est le complément plus que jamais indispensable, et il bénéficie normalement de l'expansion. Les crédits consacrés à la culture ont désormais justification objective.

Nous voici fort loin de la politique des Beaux-Arts de la République* française depuis 1871 : lorsqu'on l'étudie ${ }^{1}$, on est atterré de voir qu'il s'agit non pas d'une politique mais d'un résidu de tâches, sans lien entre elles, héritées des hasards de la politique ou de l'idéal. Comment s'étonner alors que les budgets

\section{IVe République : le «temps de l'espérance contrariée »}

Dans le Préambule de la nouvelle Constitution, votée en 1946, la IVe République garantit solennellement « l'égal accès de l'enfant et de l'adulte [...] à la culture». De fait, dès la fin des années 1940, sont créés les centres dramatiques, le Centre national de la cinématographie, les festivals de Cannes et d'Avignon... Pourtant, lors de la décennie suivante, cet élan s'interrompt, au point que l'historien Philippe Poirrier a pu qualifier cette période de «temps de l'espérance contrariée ". Au cours des années 1950, des voix s'élèvent - Jeanne Laurent, Robert Brichet... - pour réclamer la création d'un ministère spécifiquement dédié aux « affaires culturelles ». En 1959, la Ve République naissante exaucera ce vœu. soient allés en s'amenuisant ${ }^{2}$ ? Quelle assemblée, quelle administration financière raisonnable pouvaient admettre de dépenser l'argent rare de la nation pour des mesures sans suite, purement subjectives, fondées seulement sur la générosité et le goût de quelques personnages passagers?

En renversant la démarche qui permet de définir une politique culturelle, on met un terme à l'ère des «goûts et des couleurs». Un fondement objectif est trouvé à l'affectation des crédits : des critères sociaux d'intervention peuvent être utilisés, des priorités définies, des programmes pluri-annuels établis. Ainsi, ce qui est neuf dans l'aventure commençante de la planification culturelle, ce n'est pas tant la possibilité de programmer sur quatre ans des opérations définies antérieurement, ni même d'arrêter des priorités dans les tâches à accomplir : c'est cette révolution dans l'attitude vis-à-vis de la culture où apparaît enfin l'objectivité. En cela, cette attitude peut être dite scientifique.

\section{CE QUi ne SE PROGRAMMERA JAMAIS}

Il reste - bien sûr - que les démarches scientifiques de la planification ne peuvent que préparer la décision et non la commander, et que seule une volonté politique peut promouvoir une politique culturelle.

Il reste surtout que l'action de quelques créateurs courageux et de quelques animateurs inventifs va plus loin, plus vite que les meilleurs raisonnements des « organisateurs ».

Il reste enfin que la culture d'une société est affaire de diffusion certes, mais mieux encore œuvre individuelle et collective de création. Ce qui se passe alors, et ce qui est communiqué, met en jeu ce qui fait la valeur de l'existence des hommes. Il y a là un primat absolu auprès duquel tout le reste est service.

Mais la culture saura toujours tracer la ligne que la science et l'organisation ne peuvent franchir. Elle ne le fera que trop aisément. Pour l'heure, c'est vers la science et l'organisation qu'il faut pousser le pendule.

1. Cf. Jeanne Laurent, la République et les Beaux-Arts, Paris, Julliard, 1995 [rééd.].

2. Le budget des Affaires culturelles représente, dans le budget total de l'État, 4,6 $6^{0 / 00}$ en $1909,3,2^{0 / 00}$ en 1939 et $3,1^{0 / 00}$ en 1964.
Source: L'Expansion de la recherche scientifique. Revue trimestrielle de l'Association d'étude pour l'expansion de la recherche scientifique, n²1, décembre 1965, «Des chiffres pour la culture. Colloque de Bourges », 40 p. À côté d'Augustin Girard, ont participé à ce numéro Joffre Dumazedier, Pierre Bourdieu, Paul Chombart de Lauwe et alii. Préfaces d'André Holleaux et de Bertrand Girod de l'Ain. Ce texte a fait l'objet d'une réédition dans l'ouvrage Trente ans d'études au service de la vie culturelle publié par le ministère de la Culture et de la Francophonie à l'occasion du départ à la retraite, le 8 mars 1993, d'Augustin Girard (document disponible auprès du Comité d'histoire). 


\title{
Développement culturel et politique culturelle
}

\author{
Quelques mois après le printemps 1968, Augustin Girard publie dans la revue du Conseil de la \\ coopération culturelle du Conseil de l'Europe et de la Fondation européenne de la culture un article \\ préfigurant l'évolution que connaîtra en France, au début de la décennie suivante, la politique \\ culturelle de l'État. Au centre de cette réflexion, la notion de "développement culturel* », emprun- \\ tée à Joffre Dumazedier.
}

«Il n'y a pas accouplement plus sot que celui des mots développement culturel », disait un professeur à la Sorbonne ! Comme si la culture, qui représente à la fois les valeurs les plus hautes de la société et ce que chaque homme porte en lui de plus intime, pouvait être «développée » à la manière de la production d'acier! Pas une réunion nationale et a fortiori internationale, où les quatre cinquièmes du temps ne soient perdus à liquider des malentendus sur les acceptions du mot « culture ». Chacun « sait », bien sûr, ce qu'est la culture. Chacun a, là-dessus, son expérience personnelle, son système de valeurs : faibles chances que l'objectivité pénètre le discours. Or, il n'y a pas de discours collectif, de réunion de travail, de progrès dans l'analyse, d'accumulation d'expérience, bref d'organisation internationale, sans un consensus minimal sur les concepts. Aussi n'est-ce point par goût des mots, mais par nécessité que nous verrons dans cet article l'occasion de préciser le sens de ce concept barbare qu'est le « développement culturel». On ne peut travailler sans outil. Le Conseil de l'Europe, dès lors qu'il décide d'être un organisme de coopération technique, n'échappera pas à la nécessité de se forger un outillage conceptuel. Sans cet outillage commun, Babel restera Babel.

Qu'on se rassure: nous n'ajouterons pas ici une nouvelle définition de la culture aux deux cents définitions anthropologiques du mot et aux myriades de définitions «humanistes ». Ce que nous recherchons, par l'expression « développement culturel», c'est un concept opérationnel : ce concept ne se situe ni au plan philosophique des valeurs, ni même au plan de l'analyse anthropologique, mais au plan de l'action. Il vise, dans le processus de développement de la société - processus spontané ou orienté - la part non économique et non purement sociale de ce développement.

C'est donc un secteur immense du développement qui comprend trois aspects; 1 'accès et la participation aux connaissances (qui relève principalement de l'école et de l'Université); l'accès et la participation au monde présent (qui relève principalement des moyens d'information); l'accès et la participation au monde des valeurs (qui relève principalement de l'action culturelle) $[\ldots]$

\section{DÉMOCRATISATION CULTURELLE}

Le principe moteur du développement culturel est d'abord, comme pour l'école, la démocratisation. L'apprentissage culturel, en effet, est loin d'être offert également à tous les membres de la société. Les inégalités culturelles sont les plus tenaces : même lorsque le plombier gagne autant que le professeur d'université, il reste qu'à l'Est comme à l'Ouest, les chances de leurs enfants d'accéder à la culture sont très différentes.

Or, la démocratisation culturelle a deux aspects : il s'agit d'abord que chacun, à quelque couche qu'il appartienne, ait les mêmes chances d'accès que celui qui était autrefois privilégié, par son instruction, sa famille, son niveau de vie. Or, les barrages sont nombreux : frais, éloignement et, surtout, langage et mentalité. Les institutions du développement culturel sont faites pour bousculer ces barrières.

Jusqu'à présent, les échecs ont été beaucoup plus nombreux que les succès : les institutions créées dans un but de démocratisation - théâtres populaires, Maisons de la culture, etc. - ont beaucoup plus souvent abouti à cultiver ceux qui l'étaient déjà qu'à gagner à la culture les masses qui l'ignorent. On voit dès lors que le développement culturel ne consiste pas à proposer des équipements qui ne font que «surprivilégier» les privilégiés mais à inventer tout un ensemble de mesures qui s'adressent à tous les âges, à toutes les catégories, en tous lieux.

\section{Développement culturel}

Afin de faire connaître à un public élargi les résultats de ses travaux et enquêtes, le Service des études et recherches lance en 1969 un bulletin périodique dont le titre, Développement culturel, dit bien les concepts de politique culturelle dont se réclament ses promoteurs. Lorsque, en 2007, ce bulletin disparaît pour laisser place à quatre nouveaux titres - Culture études, Culture chiffres, Culture prospective et Culture méthodes -, la collection comptait, non compris les numéros hors série, plus de cent cinquante livraisons. 


\section{DÉMOCRATIE ET CRÉATION}

La démocratisation de la culture a un second aspect qui concerne non plus ceux qui la reçoivent, mais ceux qui la font: les sociétés démocratiques doivent prendre la place des princes et des évêques pour faire vivre les artistes ; or, il y a antinomie entre l'organisation majoritaire de la démocratie et la solitude novatrice du créateur : comment surmonter cette antinomie ? Comment relier le créateur à la masse des nouveaux demandeurs de culture ? Comment faire pour que ceux-ci, lorsqu'ils accèdent à la culture, n'accèdent pas seulement à celle du passé, mais directement à celle qui est en train de se faire ? Voilà une seconde tâche du développement culturel.

\section{Des POLITIQues CUlTURELleS}

Ces tâches de diffusion et de création, lorsqu'elles sont conçues à l'échelle de la population tout entière, posent des problèmes qui sont d'une tout autre ampleur que ceux de la gestion des Beaux-Arts d'antan. Il ne s'agit plus de distribuer quelques subventions aux

\section{Le «développement culturel »}

Née des réflexions suscitées au sein des mouvements de l'éducation populaire - et notamment du mouvement «Peuple et Culture »-, la notion de «développement culturel » trouve sa première formalisation en 1964, lors des Rencontres d'Avignon organisées, dans l'environnement du festival, par Jean Vilar (cf. p. 30-31). En décembre de la même année, à l'occasion du colloque de Bourges, Joffre Dumazedier en propose la définition suivante: "C'est dans les conditions d'une société de masse peu à peu gagnée par la consommation de masse que nous avons à poser le problème du développement culturel dès aujourd'hui [...] Le développement culturel se définit comme une mise en valeur des ressources physiques et mentales de l'homme en fonction des besoins de la personnalité et de la société. " Et de préciser: "Sur le plan de la recherche, cette réflexion aboutit à souhaiter le développement de sciences sociales de l'action culturelle fondée sur une difficile mais nécessaire alliance de la recherche historique et de la recherche opérationnelle. " Après Mai-1968 et le départ, au printemps suivant, d'André Malraux, la nécessité se fait jour d'une inflexion de la politique culturelle de l'État. C'est à Jacques Duhamel qu'il revient de mettre au cœur de la nouvelle politique culturelle la notion de "développement culturel». Le 2 décembre 1971, lors de l'installation du «Conseil du développement culturel ", le ministre la définit ainsi : "Le développement culturel est une dimension du développement social, si l'on entend par là l'épanouissement optimal des individus et des groupes dans une société en quête de mieux-être et d'égalisation des chances. À ce titre, le développement culturel est une affaire politique : il intéresse donc l'État [...] L'amélioration des conditions de vie, de travail, de transport et de loisirs est la base même du développement culturel. J'ai dit un jour que la culture, c'est ce qu'il fallait pour qu'une journée de travail soit une vraie journée de vie. " D'où une politique qui n'a plus seulement pour ambition de "rendre accessibles les œuvres capitales [...] au plus grand nombre » mais de fournir «à la totalité des citoyens le minimum vital en matière culturelle [...] Les hommes ont même le droit de refuser la culture, mais ils sont en droit d'exiger qu'on la leur propose et que l'égalité en droit, l'égalité de chances soit en ce domaine accomplie». artistes ou aux théâtres, ni d'agrémenter le luxe des puissants, il s'agit d'une action décentralisée, ramifiée jusqu'au dernier petit groupe d'individus, d'une action continue, cohérente, de longue haleine. C'est pourquoi l'on peut et l'on doit parler de développement culturel, comme on parle de développement social et de développement économique.

C'est pourquoi aussi la notion de développement culturel implique qu'un ensemble de principes et de moyens soient mis sur pied, concernant l'État, les collectivités locales et les groupes de citoyens, que des budgets soient calculés, votés, répartis, bref qu'il y ait une politique culturelle comme il y a une politique sociale et une politique éducative.

\section{LA TÂCHE DU CONSEIL DE L'EUROPE}

Il appartient à une organisation internationale régionale comme le Conseil de l'Europe, dès lors qu'elle met au premier plan de ses préoccupations l'éducation permanente, de rassembler les trouvailles qui sont faites dans les différents pays d'Europe, d'en dégager les caractères transmissibles, d'en tirer les conclusions de politique générale qui pourront éclairer chacun des pays membres.

\section{La coopération culturelle en Europe}

Dans le contexte de la « guerre froide », le Conseil de l'Europe, quoique dépourvu de réels moyens d'investigation, constitue alors une des rares institutions internationales où peuvent se rencontrer et échanger des représentants des deux blocs.

Qu'il s'agisse d'aide à la création, de formation d'animateurs et administrateurs culturels, d'esthétique urbaine, ou d'utilisation culturelle de la télévision, chaque pays d'Europe, aussi développé qu'il soit, a besoin d'assistance technique pour son développement culturel. Par ses comités d'experts, ses contacts avec les gouvernements, le Conseil de l'Europe peut être - et doit être - ce lieu de construction d'une politique européenne de développement culturel [...] Certes, il ne s'agit point de «mettre en politiques » la culture proprement dite, car celle-ci est valeur propre à chaque pays. Sa richesse tient à sa liberté. Mais ce qui doit être mis en commun, ce sont les pratiques de gestion, les modalités de l'encouragement, les moyens de la démocratisation. Il ne s'agit pas, bien sûr, de développer la culture, car elle est du domaine de l'esprit, mais de développer ses moyens, ses supports matériels qui sont du domaine des affaires politiques.

Source : Éducation et Culture, n 8 , numéro spécial, automne 1968 , p. 11-12 [revue du Conseil de la coopération culturelle du Conseil de l'Europe et de la Fondation européenne de la culture]. 


\section{Pour une politique de la lecture}

Le ministère des Affaires culturelles d'André Malraux, le "ministre-écrivain », n'a pas de compétence administrative dans le secteur du livre et de la lecture, resté de la responsabilité du ministère de l'Éducation nationale - la tutelle ne sera transférée au secrétariat d'État à la Culture qu'en 1975. Cependant, Augustin Girard, dès 1968, plaide vigoureusement en faveur d'une véritable politique dans ce domaine.

Depuis 1959, l'accès des Français à la culture fait l'objet d'une politique délibérée. Il existe une politique du théâtre, une politique de la musique, une politique des musées, du cinéma, des maisons de la culture, et il existe des administrations et des budgets pour les mettre en œuvre.

Il n'existe pas de politique de la lecture et du livre. Or, le livre est, de tous les moyens d'accès aux œuvres capitales de l'humanité, le seul qui réunisse les qualités suivantes :

- la valeur esthétique la plus haute;

- la plus grande liberté de choix pour le public ;

- une participation personnelle active de chacun ;

- un prix bas;

- un volume réduit ;

- une décentralisation extrême.

[...] Le théâtre de qualité touche environ $10 \%$ des Français ; $2 \%$ des ouvriers. Pendant ce temps, $33 \%$ des ouvriers, $15 \%$ des agriculteurs lisent des livres. Le public du livre (48\% des Français) est au moins cinq fois plus étendu que celui du théâtre.

Quantitativement, le livre est donc, avec la télévision, la presse et le cinéma, le principal moyen d'accès à la culture. Psychologiquement, il est plus valorisé que les trois autres media, car tout homme sent profondément que le type d'effort personnel que requiert le livre est celui-là même que requiert une culture vraie.

Par rapport à la télévision, à la radio, le livre est un moyen de communication qui n'est pas imposé, mais choisi. Il ne donne pas lieu à saturation, à consommation indiscriminée comme les autres moyens d'information. Dans la perspective - qui nous attend d'un univers mental sursaturé par les moyens de diffusion, sursollicité, le livre est l'un des outils les plus sûrs d'une culture personnelle.

Contrairement à ce qui se passe dans le domaine plastique, sa qualité ne diminue pas avec l'abaissement du coût de production ni avec la multiplication des exemplaires. Il permet la plus haute qualité artistique au prix d'un infime objet de consommation. On a $L a$ Guerre et la Paix pour le prix d'un paquet de tabac.
Enfin, le livre va partout. Il n'est pas lié, comme la diffusion par le spectacle, à l'existence d'une collectivité de plusieurs dizaines de milliers d'habitants. Il entre et reste dans la ferme la plus isolée.

Cependant, il n'existe pas de politique de la lecture et du livre.

«Politique de la lecture » ou «politique du livre»? Les deux, mais en les distinguant. Une politique du livre est une politique de l'offre - une politique de l'édition et de la librairie - alors qu'une politique de la lecture est une politique de la demande, du public. Or, la demande est ce qui intéresse d'abord une politique d'action culturelle moderne, c'est-à-dire une action qui vise à élargir le nombre de ceux qui ont accès aux livres.

Le principe de toute politique culturelle est de jouer dialectiquement entre l'offre et la demande, et la technique de l'action culturelle, l'art des animateurs, est de concilier deux soucis antinomiques : la qualité de ce qui est proposé, la quantité du public atteint. Une politique de la lecture consistera donc à accroître le nombre des lecteurs tout en augmentant la qualité de leur lecture.

On sait aujourd'hui que $13 \%$ des lecteurs lisent des livres «de qualité », que $35 \%$ lisent des livres - sans plus - et que $52 \%$ des Français ne lisent aucun livre. Le but d'une politique de la lecture sera donc de faire passer les lecteurs de la seconde catégorie dans la première catégorie et ceux de la troisième dans la seconde.

On voit aussitôt combien cette politique de la demande retentit sur celle de l'offre, c'est-à-dire sur la production et la distribution des livres. Or, une politique de l'offre n'est pas moins nécessaire aujourd'hui que la politique de la demande : l'édition et la librairie se trouvent, devant une société qui change vite, avec des modes d'organisation qui datent largement du XIX ${ }^{\mathrm{e}}$ siècle. L'adaptation aux exigences nouvelles de cet appareil économique, lourd, disparate et dispersé 
se fera-t-elle naturellement ou se fera-t-elle rationnellement? Tout le développement de l'économie moderne montre que l'introduction d'une certaine rationalité dans une branche permet seule son adaptation rapide. On voit mal pourquoi il n'en serait pas ainsi du livre. Or, qui parle de rationalité parle d'une politique.

Il est du reste illusoire de penser qu'on peut se passer d'une politique, car, en fait, puisque chaque année il se dépense des millions de francs dans le domaine du livre, il existe une politique implicite. La différence entre celle-ci et une politique explicite, c'est que :

1. les objectifs ne sont pas clairs,

2. les moyens ne sont pas cohérents,

3. elle est au jour le jour.

Le passage à une politique explicite conduirait à une action à plus long terme, à une utilisation concertée des moyens, à l'intégration de la lecture dans la politique d'action culturelle. Le public s'en trouverait mieux, les professionnels n'auraient pas à le regretter. Que peut souhaiter d'autre la puissance publique?

[...] Une politique de la lecture ne doit pas dissocier vente des livres et prêt des livres : il n'y a pas d'un côté les bibliothèques, de l'autre les librairies, et puis encore les commerces non spécialisés. Il faut voir les trois à la fois et penser « points de diffusion ». On verra alors mieux se répartir les rôles de chaque catégorie, compte tenu de la société nouvelle.

Car on n'est plus en 1880 : le niveau de vie fait que le livre n'est plus un bien rare, cher, d'accès quasi impossible: on n'est plus au temps où le fils de paysan ou d'ouvrier n'avait que la bibliothèque publique pour accéder aux œuvres. La production et la distribution de masse permettent de très nombreux contacts avec le public et il est peut-être plus efficace de faire appel aux vertus du commerçant qu'à celles du fonctionnaire.

[...] Il est clair que la puissance publique ne peut se désintéresser de cet ensemble d'actions et il est évident qu'elle ne s'en désintéresse pas en fait. Elle ne peut pas ne pas intervenir : mesures fiscales pour l'application de la TvA, achats des livres scolaires par l'intermédiaire des librairies, plan pour la lecture publique, protection des droits d'auteur, etc.

Or, quelle est l'autorité qui prend ces mesures en fonction d'une vue globale de la branche et de son rôle dans la politique culturelle de l'État ? Elle n'existe pas.

Plusieurs rapports officiels ont souligné que le livre et la lecture relèvent de six directions administratives différentes dont aucune n'a un rôle de coordination. En fait, la tutelle est exercée par le ministère de l'Industrie, au titre des « industries diverses ». Le livre est un produit industriel parmi d'autres ${ }^{1}$ !

Or, une politique du livre et de la lecture ne saurait être une politique industrielle!

[...] Qui centralise les statistiques ? Qui coordonne mesures législatives et fiscales? Qui commande les recherches nécessaires à une modernisation de la branche? Qui prépare et définit les grandes orientations de la lecture et du livre, compte tenu de la politique culturelle du pays?

Le problème est pourtant simple et classique. Une direction de la lecture et du livre est facile à concevoir. L'assortir d'un Conseil supérieur de la lecture et du livre où siègeraient côte à côte des représentants de la puissance publique, des professions et du public est chose normale.

Il ne s'agit pas de constituer une bureaucratie nouvelle ni de la substituer à ce qui existe dans le secteur privé ou dans le secteur public, mais de créer une petite cellule de coordination, de recherche, d'information et d'impulsion. C'est peu par rapport à une affaire de grande conséquence. Ce serait déjà beaucoup.

À eux deux, ces deux organes élaboreraient une politique de la lecture cohérente, continue et efficace. Une lacune grave serait comblée dans la politique culturelle française. L'avenir culturel de la nation serait plus clair.

1. Jusqu'en 1959, la tutelle du cinéma était également assurée par le ministère de l'Industrie. Mais, à la création du ministère des Affaires culturelles, le cinéma lui a été rattaché, à juste raison.

\footnotetext{
Source: Le Livre et la lecture en France, Paris, Les Éditions ouvrières, 1968, 342 p. [coll. «Vivre son temps », no 19]. Ont participé à cet ouvrage: Jacques Charpentreau, François Clément, André Conquet, André et Geneviève Gentil, Pierre Grosz, André Harotte, Jean Hassenforder, Georges Jean, Henri Lebachelier, Michel Lobrot, Geneviève Patte.
} 


\title{
Pour une nouvelle stratégie de la culture
}

\author{
Du 7 au 11 avril 1972 se tient dans les salines royales d'Arc-et-Senans* un colloque européen inti- \\ tulé "Prospective du développement culturel ». Objectif : préparer la première conférence des ministres \\ européens de la Culture, programmée le 9 juin suivant à Helsinki. L'année suivante, dans une publi- \\ cation du Conseil de l'Europe, Augustin Girard présente un texte en forme de "discours de la méthode » \\ qui précise la position défendue au cours de ce colloque par la délégation française.
}

\section{ArC-ET-Senans -}

\section{LA LOGIQUE DU COLLOQUE}

L'ambition était grande : il s'agissait de fournir aux ministres qui allaient se réunir sur le sujet des politiques culturelles une plateforme commune qui puisse fonder à la fois l'importance de leur rôle dans l'action gouvernementale, et la structure - à renouveler - de leur action budgétaire. Il fallait qu'ils revinssent de la Conférence d'Elsinki [sic] grandis par rapport à leurs collègues de gouvernement, et plus armés s'agissant des politiques à mettre en œuvre.

Pour un ministre de la Culture, dépenser des crédits budgétaires sans expliciter des finalités sociales, c'est à la fois se condamner à les voir contester pour leur montant total au niveau gouvernemental ou parlementaire, et s'obliger, quant à la gestion, à reconduire l'ancien sans adaptation de la politique aux besoins nouveaux d'une société en changement rapide.

Pour expliciter ces finalités sociales avant la conférence, la meilleure méthode parut donc de recourir à des «futurologues » et à des « sages » de divers pays, en veillant à ce que leur observation de l'évolution de la société se fondât sur des disciplines bien différentes (économie, histoire, sociologie, théologie, linguistique, psychanalyse).

La méthode prospective, qui était proposée, avait pour but d'éviter le débat d'idées ou la confrontation éthique sur la notion de culture : débat sans fin parce que les concepts ne sont pas encore élucidés; rares sont ceux qui distinguent clairement la «culture» au sens anthropologique du terme, de la «culture» comme patrimoine et de la «culture » comme attitude personnelle et apprentissage. Mille définitions circulent, et il n'est point de débat qui ne donne l'occasion de forger une nouvelle définition élégante, vivante, vécue, mais dépourvue de rigueur conceptuelle.

Le principe du colloque fut donc que la considération du futur permettrait de dégager un consensus libéré des préalables idéologiques ou éthiques. Analyser les tendances irréversibles des sociétés indus- trielles et imaginer le rôle que prendrait la vie culturelle devant des développements technologiques pesant d'un poids très lourd sur les individus, a paru la méthode la plus objective pour déterminer les grandes finalités que devraient s'assigner les ministères de la culture dans les dix ans à venir [...].

\section{PourQuoi un déBAT}

\section{SUR LA CROISSANCE ?}

À première vue, le débat sur la croissance paraît économique plus que culturel. L'originalité du colloque d'Arc-et-Senans a été de renverser cette logique : s'il y a débat sur la croissance dans les pays industriels, ce n'est pas que cette croissance soit économiquement inviable, c'est qu'elle est culturellement invivable [...] L'économie a ses lois. Elle dicte ses contraintes, même dans les pays qui ont refusé depuis longtemps le jeu du libéralisme. Découvrir de nouvelles finalités sociales, privilégier des modes de vie nouveaux, définir des priorités nouvelles ne saurait être l'affaire de l'économiste, dont le souci est, tôt ou tard, la rentabilité ; le bonheur des citoyens n'est pas son affaire, c'est la leur. Mais pour que les citoyens deviennent pleinement maîtres de leur bonheur à revendiquer, ils doivent être mis en route, et seule l'action culturelle peut créer ce mouvement [...].

\section{LA CRISE CULTURELLE}

[...] La difficulté, dès lors que l'on veut en conséquence établir des politiques «culturelles », vient de ce que la culture elle-même est en « crise» [...] Cette crise naît de l'effacement des valeurs communes, des concepts communs de l'homme et de la société qui ont marqué le Moyen Âge et le classicisme européens. On se trouve devant une pluralité des systèmes de valeurs différents, propres à des milieux culturels très différenciés selon leur niveau d'évolution. Chaque Européen se trouve en face de plusieurs modèles de culture dont il participe simultanément: le vieux modèle rural, le modèle industriel, et déjà chez les

\footnotetext{
* Voir encadré page 15
} 
jeunes, un modèle post-industriel en plein devenir. De plus en plus, les jeunes manifestent une volonté de rupture à l'égard des modèles humanistes traditionnels. Ils refusent ce qu'ils considèrent une culture dominante qui pèse sur les subcultures nouvelles et tend à imposer une grammaire et une organisation qui leur sont devenues étrangères.

C'est cette situation de crise qu'une action culturelle doit gérer. Elle doit donc, par priorité :

1. faciliter l'expression des subcultures;

2. développer les conditions d'une autodidaxie, au sens large du terme;

3. réorienter les industries culturelles.

\section{LIBÉRER LES SUBCULTURES}

L'individu éprouve de moins en moins, semble-til, un sentiment de solidarité pour la société globale. Déjà, quand il ne se referme pas sur lui-même, il n'est relié qu'à de petits groupes. L'Europe passe déjà d'une société spécialisée, hiérarchisée, centralisée, à une société plus polyvalente, de faible hiérarchie et à centres multiples.

Ces petits groupes humains, ces subcultures secrètent des richesses de créativité qui ne sont pas «assez délivrées ». Il faut les aider, afin que le passage d'un système univoque à des systèmes pluriels (pluralité des organisations, pluralité des grammaires) enrichisse la vie culturelle, crée de nouvelles cultures. Donner la parole aux minorités qui n'ont pu jusqu'ici s'exprimer (les jeunes, les femmes, les immigrants par exemple) apparaît une tâche capitale et qui demande de l'imagination.

\section{DÉVELOPPER L'AUTODIDAXIE}

Cela suppose que soient formés des individus capables d'initiative, autonomes, critiques, chercheurs de sagesse. L'individu d'aujourd'hui est soumis à un bombardement d'images et de sons qui tue l'initiative. Pour qu'il ne se laisse pas écraser, qu'il domine l'information qui lui est offerte, il faut qu'il apprenne à connaître les grammaires des nouveaux media et acquière de nouveaux principes d'organisation de ses connaissances $[\ldots]$.

\section{MAÎTRISER LES INDUSTRIES \\ CULTURELLES}

Une grande partie de la vie culturelle sera de plus en plus préfabriquée par des industries culturelles. Elles obéiront comme les autres industries aux lois du profit maximal quand elles seront privées, et aux lois de «l'audience maximale » lorsque, comme certaines télévisions, elles seront publiques.

La critique n'est plus à faire de la surcharge sensorielle et mentale que ces industries provoquent ou de la violence finale de leurs «agressions multiples». Elles ne permettent pas une réelle motivation de l'individu. Alors que les apprentissages anciens procédaient par efforts successifs, c'est par effraction qu'elles opèrent.

La psychologie de l'individu devant ces nouveaux media est peu explorée. Quels sont les éléments qu'il retient des « informations » qui lui parviennent? Quels sont les facteurs d'acceptation, de rétention, de neutralisation, de désaffection, d'oubli ? Par l'intermédiaire des nouveaux mass media les relations inter-personnelles peuvent-elles s'intensifier? Quel sera le comportement de l'individu devant la possibilité de se constituer des «stocks » audio-visuels ? Comment utiliser au profit de la culture les industries culturelles, elles qui utilisent la culture à leur profit ? Comment donner aux industries culturelles des objectifs qui les rendent productrices de vie sociale? Autant de questions qui méritent études et expériences dès maintenant.

\section{De la FUTURologie À LA POLITIQUe}

[...] Quels que soient les crédits engagés pour démocratiser le théâtre, la musique, les arts plastiques, le public reste le même, privilégié de la fortune et de l'instruction, et la masse de ceux qui sont exposés aux mass media et à la publicité ne participe pas à une vie culturelle, que les institutions leur proposent. L'effort remarquable des centres culturels de toute sorte mord à peine sur la réalité sociale. Des générations de jeunes sont condamnées à l'alternative : intégration résignée à un système honni, ou révolte sans espoir. Dans la société qui est en train de naître, c'est la culture traditionnelle qui devient marginale tandis que des majorités silencieuses ou bruyantes ne sont pas mises en état d'inventer leur propre culture [...] Lorsque les budgets culturels augmentent, ce sont des institutions dépassées qui en profitent; opéras qu'on redore, musées qu'on dépoussière, théâtres qu'on bureaucratise. Les formes nouvelles de création et d'animation, les lieux inédits où la jeunesse se rencontre et s'exprime, les techniques de pointe restent à l'écart du cheminement des subventions officielles. Alors que le futur est déjà là, on aide le passé. Mais les gouvernements ne s'aperçoivent de rien, les parlementaires grognent sans produire aucune alternative, tandis que la machine sociale se borne à reproduire d'année en année sa marche inconsciente.

Le Conseil de l'Europe pourrait être le lieu d'une conscience de la crise qui ne peut que frapper chaque pays, l'un après l'autre [...] Recycler ministres, parlementaires, hauts fonctionnaires, extraits pour quelques instants de leurs tâches de gestion, est une mission urgente dont les moyens devraient être considérables $[\ldots]$.

Source: Éducation et Culture, n² 22, numéro spécial, été 1973 p. 6-10 [revue du Conseil de la coopération culturelle du Conseil de l'Europe et de la Fondation européenne de la culture]. 


\title{
Prospective du développement culturel
}

\author{
Le titre de cet article reprend l'intitulé du colloque organisé en avril 1972 à Arc-et-Senans*. Reve- \\ nant sur les problématiques évoquées l'année précédente, Augustin Girard souligne la nécessité, \\ pour les responsables des politiques culturelles, de tenir, face à la crise de civilisation, un discours \\ «qui engage».
}

[...] Le besoin de prospective en matière de développement culturel est né de la grande incertitude qui pèse sur l'établissement de politiques culturelles efficaces. L'échec de la démocratisation de la culture apparaît aux ministres des pays qui s'occupent le plus d'affaires culturelles ; ils ont beau augmenter les crédits : en augmentant les crédits, ils renforcent le poids des institutions culturelles qui, justement, ne touchent pas la population qu'ils recherchent. En Suède, on a multiplié par deux les crédits des musées et on s'est aperçu qu'en cinq ans le public était resté inchangé. En France, voulant donner une impulsion au théâtre, on a multiplié par trois et quatre les crédits au théâtre. À quoi a-t-on abouti ? Le directeur de la ComédieFrançaise a maintenant une limousine noire qui vient se ranger à côté de celle du ministre dans la cour du Palais-Royal.

Les ministres ont besoin d'une remise en cause de la façon dont leurs crédits sont répartis, soit par secteurs, soit par fonctions - fonctions de création, de diffusion, d'animation, de conservation. Ils ont besoin d'argumenter la nouvelle place du budget de la culture dans le budget national, ou bien la nouvelle place d'un ministère de la Culture par rapport aux autres grands agents culturels que sont les mass media, les industries culturelles ou les autres administrations (l'Éducation, l'Aménagement du territoire, l'Équipement, etc.).

Quels sont les critères de cette nouvelle mise en place ? Il n'y en a pas. Le plus souvent, l'organisation de la vie culturelle est simplement un reliquat, une sorte d'habitude ancienne. Les institutions se bornent à reproduire la forme sociale qui les a conçues. Donc, le recours au «futur» est le seul recours.

[...] Notre objectif [est] de découvrir une sorte de discours sur les finalités, qui puisse être reçu, adopté, fait leur par des responsables des politiques culturelles de nos différents pays d'Europe. Mais un discours qui engage finalement, car, contrairement peut-être à ce que disait de Certeau, j'ai observé qu'il y avait des discours votifs et des discours qui engagent. L'action planificatrice n'est pas une préparation de la décision qui interviendrait tout d'un coup ! En fait, c'est un vaet-vient ! C'est un mixte, et dans ce mixte le discours,

\section{Arc-et-Senans, « centre du futur »}

Transformées en un « centre culturel de rencontre » consacré à l'étude du futur, les salines d'Arc-et-Senans accueillent en avril 1972 une vingtaine de participants, futurologues et chercheurs de diverses disciplines venus d'une dizaine de pays. Parmi eux figurent l'anthropologue Michel de Certeau, auteur du rapport introductif ( "La culture dans la société ») qu'il développera en 1974 dans son livre La Culture au pluriel; le sociologue Edgar Morin, de retour de Californie, dont le diagnostic sur la «crise culturelle » nourrit les réflexions du ministère Duhamel ; le futurologue Alvin Töffler, auteur du Choc du futur, etc. Dans leur avant-propos, les responsables de la revue Analyse \& Prévision présentent ainsi la problématique de ce numéro : "La crise de civilisation pose aux gouvernements des problèmes qui ne relèvent plus seulement de l'économie et du droit mais appellent des stratégies sociales nouvelles et l'élaboration de politiques culturelles explicites. Or, l'action menée par les États dans le domaine culturel repose encore le plus souvent sur des habitudes héritées du passé [...] Elle ne trouve pas encore à s'appuyer sur un ensemble de finalités précises qui pourraient être tirées de l'évolution prévisible de nos sociétés et faire l'objet d'un consensus. »

que sous-tend une utopie directrice, joue un rôle constant.

[...] Dans un colloque comme le nôtre, il ne peut pas s'agir de définir une politique. Ce n'est pas, en effet, l'affaire des observateurs de la vie sociale que de définir une politique. La politique est définie par le pouvoir qui prend ses responsabilités, et dans un jeu de pouvoir. Mais ce que l'observateur peut faire, c'est de définir les objectifs des politiques ou de dire quels seraient les prolégomènes à toute politique culturelle future. Là, il y a un discours international possible. C'est ce que notre colloque est appelé à rechercher, ouvrir des hypothèses nouvelles, permettre des remises en question totales, compenser les oublis. Mais, quand on ouvre ces hypothèses, il faut bien prendre soin que l'on puisse, ensuite, les projeter sur la carte sociale, sans quoi, effectivement, le discours reste en l'air.

Source: Futuribles. Analyse \& Prévision, $\mathrm{n}^{\circ}$ hors série, octobre 1973, 206 p., p. 9-12 (dossier «Prospective du développement culturel »). Ont participé à ce numéro, outre Augustin Girard : Kerstin Aner, René Berger, Hubert Brochier, Michel de Certeau, Jennie Lee, Yrjö Littunen, Abraham Moles, Jesus Moneo, Edgar Morin, C.A. Van Peursen, Georg Picht, Emmanuel Pouchpa Dass, Pierre Riches, Lionel de Roulet, Craig Sinclair, Paolo Terni, Umberto Terrazini, Alvin Töffler. Préface d'Augustin Girard. 


\section{Industries culturelles}

Quelle est l'efficacité comparée des politiques publiques de démocratisation de l'accès à la culture et des moyens nouveaux de diffusion de l'écrit, de l'image et du son? Telle est la question au cour de cet article. Les relations de plus en plus fortes et complexes que la politique culturelle entretient avec les industries culturelles* y sont analysées et les mutations de celles-ci déjà décelées.

On assiste depuis quinze ans à trois phénomènes concomitants :

- multiplication par deux, cinq ou dix, selon les pays, des dépenses publiques en faveur de la vie culturelle, en vingt ans ;

- stagnation cependant de la fréquentation des institutions culturelles ;

- multiplication par vingt, cent ou mille des contacts entre les œuvres et le public grâce à des produits culturels industriels.

Ces trois phénomènes simultanés posent problème aux responsables culturels car toutes les politiques culturelles à travers le monde sont des politiques d'élargissement de l'accès du public à la culture : démocratisation et décentralisation sont les deux mots d'ordre partout où un effort explicite est mené par les pouvoirs publics.

\section{DÉMOCRATISATION}

\section{ET INDUSTRIES CULTURELLES}

Or, le phénomène constaté plus haut oblige à observer que le progrès de la démocratisation et de la décentralisation est en train de se réaliser avec beaucoup plus d'ampleur par les produits industriels accessibles sur le marché qu'avec les «produits » subventionnés par la puissance publique.

On arguera que ces quantifications sont abusives, qu'un produit culturel transmis ou reproduit n'a pas la même «valeur culturelle » qu'une œuvre communiquée de façon directe, en salle. Il faudrait certes différencier selon les domaines d'activité culturelle: théâtre, cinéma, musique, débats, expositions.

Mais quelle est au juste la différence d' « effet culturel » entre un film vu dans une salle de cinéma et le même film vu chez soi sur un écran de télévision (écran qui aura bientôt les mêmes dimensions qu'un écran de cinéma) ? Combien de mélomanes préfèrent désormais écouter un quatuor dans le recueillement du domicile, avec les niveaux sonores d'une chaîne à haute fidélité, plutôt que dans une salle de concerts avec toutes ses distractions, ses distorsions, ses encombres multiples ? [...] Les réponses à de telles questions doivent être examinées de très près, et abstraction faite des snobismes insidieux.
En dehors de leur impact sur la vie culturelle de la population, le développement des industries culturelles a une incidence importante sur la vie des créateurs, leurs modes de travail, leurs relations avec le public et sur les modes de production de la vie culturelle en général. L'irruption des moyens mécaniques et électroniques de reproduction, et la possibilité de toucher d'immenses publics en une seule représentation par la télévision, posent des problèmes de revenus, de droits, de mode de travail qui sont encore traités au coup par

\section{Vous avez dit « industries culturelles »?}

Si l'expression est aujourd'hui couramment répandue, c'était loin d'être le cas en 1978 - même si André Malraux en son temps et Augustin Girard lui-même, en 1972, l'avaient déjà employée -, au point que les responsables de la revue Futuribles ont cru bon de l'expliciter alors en ces termes: " Il y a industrie culturelle lorsque la présentation d'une œuvre est transmise ou reproduite par les techniques industrielles : le livre est le plus ancien de ces produits, le disque celui qui se développe le plus rapidement, le film de télévision celui qui a le plus grand public. Le film de cinéma et la reproduction d'art constituent des marchés depuis plusieurs décennies. De nouveaux produits industriels vont intervenir prochainement sur le marché de la culture et y jouer un rôle massif: le vidéo-disque par exemple. La radiotélévision est inclu[s]e dans les industries culturelles dans la mesure où son fonctionnement est commandé par des critères industriels et commerciaux plutôt que culturels: l'impératif de gagner un nombre maximal de consommateurs qui est imposé par la concurrence entre les chaînes (elles doivent se disputer les ressources de la redevance et surtout de la publicité), la considération des coûts de fabrication qui est devenue décisive pour le choix des programmes, le lien étroit entre techniques de tournage et contenus des programmes, la nécessité d'importer et d'exporter, leur rôle dans l'économie du cinéma donnent aux sociétés d'État la plupart des caractéristiques d'une entreprise industrielle. »

En fait, c'est dès la fin de l'année 1974 que la DGRST mit en place un comité scientifique présidé par Paul Delouvrier (président d'EDF), assisté d'Augustin Girard, avec l'objectif de programmer des recherches sur des politiques culturelles considérées comme «importantes et mal connues». Ce fut pour le SER l'occasion de lancer des travaux sur les industries culturelles, en particulier sur le disque (Antoine Hennion), le livre (François Rouet), la télévision (Claude Goudron), les industries audiovisuelles (Patrice Flichy). Une synthèse de ces travaux fut publiée en 1979 par la Documentation française, dans la série Notes et études documentaires, sous le titre «Les industries culturelles » ( $n^{\circ} 4535-4536$, novembre 1979, 180 p.). 
coup. En même temps, la notoriété d'un artiste passe plus aujourd'hui par les moyens industrialisés que par les plus grands succès en salle. Un organiste deviendra célèbre par ses disques beaucoup plus que par les concerts qu'il donne. En retour, sa notoriété par le disque lui permettra des tournées de concerts et le contact avec des publics dans le monde entier.

Quant aux institutions, leur rôle même est remis en cause par l'industrialisation de la culture. D'ores et déjà, le prêt d'un livre en bibliothèque coûte plus cher que le livre lui-même. Un film vu à la télévision coûte au spectateur mille fois moins cher qu'une place, et le nombre de spectateurs-films est trente fois plus grand à la télévision que dans les salles obscures. Une ville doit-elle assumer les frais d'un petit orchestre et d'une salle, ou ne dépenserait-elle pas mieux les mêmes crédits en initiant les écoliers à l'écoute de disques de qualité?

Ainsi, bouleversant les données classiques de la vie culturelle, un système industriel et commercial s'interpose entre le créateur et ses interprètes d'une part, et le public d'autre part. Ce système a ses lois propres, ses structures, ses stratégies.

Appuyées sur des innovations technologiques [...], ces industries culturelles sont de plus en plus transnationales et couvrent de produits culturels « transnationaux » des aires culturelles ou linguistiques qui sont trop restreintes pour permettre une production nationale.

Cet ensemble de faits nouveaux ne peut pas ne pas intéresser les gouvernements, soit qu'ils cherchent à trouver dans ces industries culturelles des supports pour leur politique culturelle, soit qu'ils soient amenés à contrôler les effets négatifs de ce développement du marché. On peut d'un côté se réjouir de l'élargissement du public pour des œuvres de haute qualité (livres de poche, musique en haute fidélité, par exemple), de l'amélioration des revenus des créateurs, professionnels et techniciens [...] ou encore de l'intensification des échanges culturels internationaux capables d'atteindre le grand public (les films de Bergman, les reproductions des impressionnistes, les livres d'Heinrich Böll font plus pour faire connaître et aimer la culture suédoise, française ou allemande que toute l'activité des conseillers culturels).

On peut d'un autre côté déplorer divers effets négatifs de cette production et distribution de masse: homogénéisation des produits, appel aux goûts les plus vils, écrasement des cultures minoritaires, paysannes ou régionales. Mais, positifs ou négatifs, ces effets ne sont pas bien connus. Leur valeur n'est pas appréciée de façon objective, et c'est là un premier sujet d'études, de réflexions et d'échanges.

Encore plus mal connues des pouvoirs publics sont les structures, les processus de production et de distribution ainsi que les stratégies des industries cultu- relles. Que les gouvernements décident de favoriser, ou qu'ils souhaitent au contraire contrôler davantage ces processus et ces stratégies industriels, en tout état de cause, il leur faut disposer de données claires et économiquement cohérentes. Actuellement, ils n'en disposent pas, et c'est là un second sujet de recherches.

$\mathrm{Au}$ terme d'une série d'études préliminaires (2) menées de concert par la Délégation générale à la recherche scientifique et technique (DGRST), l'Institut national de l'audiovisuel (INA) et le ministère de la Culture et de la Communication, un certain nombre de caractéristiques de ces industries peuvent être identifiées.

\section{RISQUE ET STAR SYSTEM}

Les produits culturels industriels ont en commun une caractéristique assez particulière pour des produits industriels : la probabilité du profit est négative. Statistiquement, un film, un disque, un livre ont plus de chance de faire perdre de l'argent à l'éditeur que de lui en faire gagner.

Comment se fait-il dès lors que les producteurs et les éditeurs continuent d'exister? C'est que les revenus tirés d'un succès sont tellement multipliés par rapport au coût, qu'ils remboursent - et au-delà - les pertes subies sur la moyenne des autres produits. Cette prime au succès énorme $[. .$.$] conduit à la recherche à$ tout-va du best-seller et à une accentuation grandissante du star system.

Les directeurs artistiques des firmes culturelles sont devenus, par leur sens aigu des goûts changeants du public, les personnages-clefs de ce système industriel, car l'ensemble repose sur la découverte des futures «étoiles ». Producteurs et éditeurs ne cessent de parier et bien que leur image bénéficie de «l'aura » un peu éthérée de la culture, leur comportement n'est pas toujours très éloigné de celui des propriétaires d'écuries de courses. Les industries culturelles sont des industries à risques gros.

La publicité, qui est incapable, contrairement à l'opinion naïvement reçue, de créer des vedettes, sait par contre parfaitement accompagner les succès, les gonfler et les faire durer auprès du public. Télévision et radio décuplent le succès, et les étoiles, si leur talent est suffisamment réel pour ne pas démentir l'effort publicitaire, deviennent peu à peu des valeurs sûres qui viennent grossir le catalogue, c'est-à-dire le capital culturel de la firme. Les rentrées régulières que rapporte ce capital culturel, mais surtout les best-sellers, permettent d'investir dans de nouveaux talents, qui doivent être aussi nombreux que possible, car personne ne sait à l'avance qui passera soudain la rampe vers le grand public. 


\section{TALENTS ET CAPITAUX}

En dehors des best-sellers, la source principale des revenus des entrepreneurs culturels est la distribution. C'est une source plus régulière que l'édition puisque, par définition, on distribue essentiellement ce qui a du succès : avec une bonne gestion et de bonnes messageries, les chances de perte sont minimisées tandis que les rentrées se développent au même rythme que le marché : c'est dans ce secteur-clef que s'investissent les capitaux, y compris les capitaux internationaux.

Aussi l'intérêt des entrepreneurs culturels - éditeurs de livres, de disques, producteurs de films, d'émissions - est-il que les écuries de créateurs soient aussi nombreuses et variées que possible pour multiplier les chances de succès auprès du public. Ceux qui, dans ces entreprises, détiennent les capitaux, sont donc moins préoccupés du contenu des œuvres que de leur capacité de plaire au grand nombre : ils n'ont pas intérêt à exercer une censure culturelle et souhaitent l'expression de personnalités et d'idéologies aussi diverses que possible.

Ainsi les processus classiques de concentration industrielle verticale jouent-ils moins qu' on ne pourrait le penser ; l'intérêt des entrepreneurs rejoint l'intérêt général en ce sens que plus la création est vivante, diversifiée et nombreuse, plus les chances de profit sont grandes lors de la distribution. Même lorsqu'un distributeur est aussi éditeur, il lui arrive de distribuer les œuvres d'un éditeur concurrent en priorité par rapport aux siennes propres si le succès prévisible du concurrent est plus grand.

\section{ÉLARGIR LE SABLIER}

La production des industries culturelles fonctionne selon le schéma du sablier: les créateurs sont nombreux en haut du sablier, les directeurs artistiques sélectionnent, les éditeurs prennent le risque, ensuite les média (critiques de presse, producteurs de télévision, de radio) font un second tri qui est le goulot du sablier. Puis les œuvres se diffusent sur le public par centaines de milliers de copies.

Le problème, pour une société qui veut donner plus de chances aux créateurs et le plus d'œuvres possible au public, est de desserrer autant qu'il est réaliste ce goulot d'étranglement. Pour cela, la multiplicité des petits éditeurs ou la multiplicité des directeurs artistiques semble la solution la meilleure, aussi bien pour les créateurs et le public que pour les industriels de la culture. Comme lorsqu'il s'agit des aides publiques en matière d'art plastique, c'est la multiplicité des instances de jugement et de choix qui assure la plus grande vitalité à la création.

En même temps qu'on souhaitera multiplier les petits éditeurs, on veillera à ne pas affaiblir les grandes entreprises culturelles qui sont capables de soutenir le succès jusqu'aux best-sellers, car ce sont ces best-sellers qui font vivre la branche et assurent un certain flux d'exportations vers l'étranger.

\section{INDUSTRIES CULTURELLES}

\section{ET ACTION CULTURELLE}

La schématisation qu'on a tentée plus haut des industries culturelles est bien entendu une généralisation abusive, chaque branche et chaque phase du processus de production ayant ses lois propres et ses innombrables cas d'espèce. Mais le but du présent article n'est pas de traiter le sujet - il faut se reporter pour cela aux études originales - mais de sensibiliser élus, administrateurs, professionnels et militants culturels à ce phénomène mal connu qu'est une certaine démocratisation de la culture par le jeu du marché. Si les industries culturelles ont bien l'impact que nous disons sur la vie culturelle de la population et sur les modes de production de cette vie culturelle, les responsables de l'action des pouvoirs publics ne peuvent pas ne pas essayer de tenir compte du phénomène pour la modernisation de la politique culturelle.

Les professionnels et les militants qui travaillent dans les maisons de [la] culture, maisons de jeunes et autres maillons du réseau de l'action culturelle publique s'interrogent en effet sur l'impact de leurs institutions auprès de la population comparé à l'impact des autres agents culturels que sont la radio-télévision et le commerce, Ils constatent une évolution importante dans la vie culturelle générale, prise dans son sens le plus large, qui inclut les pratiques de loisirs et de vacances ainsi que les représentations que la population se fait de la culture, et en même temps ils sont obligés de reconnaître l'emprise faible, en stagnation ou en régression, de l'animation culturelle dans les entreprises ou les quartiers. "Bien que professionnels », disent-ils, «nous bricolons, nous nous marginalisons ».

En dehors de l'intelligenzia [sic], traditionnelle ou nouvelle, la population semble plus influencée dans son évolution culturelle par l'animation commerciale et les diffusions de la télévision que par tous les efforts déployés par le réseau socio-culturel, appuyé sur les professionnels et les crédits publics. Même dans les villes où ce réseau est puissant, le phénomène est sensible : il conduit les militants - et les professionnels sont aussi des militants - à un certain découragement et à une interrogation sur la nature et le rôle de leur action.

On arrive peu à peu à la constatation paradoxale que l'animation culturelle est élitaire : elle touche des groupes peu nombreux, déjà motivés, alors que la grande majorité des classes populaires et des classes moyennes se nourrit ailleurs, autrement. [Cela] ne signifie pas que les interventions de l'animation culturelle soient des échecs: ce sont au contraire des 
réussites, au double sens de la qualité de la communication et de sa prégnance sur les individus qu'elle atteint. Un certain fil de l'esprit passe. Mais elle reste l'affaire de minorités et il n'est pas sûr qu'un doublement, un quintuplement, ou un décuplement des crédits publics résoudrait le problème : à la fois parce que la majorité du public resterait hors d'atteinte - en dix ans, on a multiplié par cinq les crédits des musées en Suède et le public ne s'est accru que de $25 \%$ - et parce que l' 'institutionalite» $[\mathrm{sic}]$ phagocyterait l'animation. Il faudrait un encadrement de la population comparable à celui du système éducatif : impossible, tant à cause de la charge insupportable pour le produit national, qu'à cause de la bureaucratisation inévitable, incompatible avec la nature même de l'action visée.

Sans qu'en aucune façon la voie ouverte par $l '$ '«action culturelle » des quinze dernières années soit reniée ou fermée, il serait intéressant qu'elle s'articule davantage avec le jeu des média et des industries culturelles. La difficulté est certes grande de jouer avec des techniques de masse, qui ont leurs fatalités anti-culturelles, mais il n'y a probablement pas d'alternative si ceux qui ont vocation à être les gardiens de la culture veulent élargir leurs contacts avec la grande part de la population. Des formules nouvelles sont à inventer, appuyées sur des techniques nouvelles: des risques sont à prendre et des échecs nombreux devront être longtemps acceptés. Mais la nécessité est là, mère de l'invention. Entre l'animation, qui met l'accent sur l'expression des groupes et la diffusion des médias industriels qui met l'accent sur les œuvres, une articulation doit pouvoir être trouvée, car elle est la charnière entre les technologies nouvelles et les nouveaux besoins sociaux, au cœur de la réalité telle qu'elle est. À ce prix, l'action culturelle sortira de l'élitisme paradoxal où ses contradictions risqueraient de la confiner.

De son côté, le secteur privé de la culture doit innover plus activement et découvrir de nouvelles voies d'accès aux œuvres pour le public le plus large. Il n'y a pas nécessairement contradiction entre le lucratif et la démocratisation, bien loin de là. Dans la branche du disque, trois petits faits montrent à titre d'exemple comment peuvent s'articuler commerce et culture : d'ores et déjà, la plus grande proportion des ventes de disques est réalisée en libre service dans les supermarchés : certes, on n'y trouve pas les superbes séries des collectionneurs de disques, mais il faut rappeler que, s'agissant de démocratisation culturelle, le libre accès et le libre service favorisent les moins cultivés : ceux-ci reculent en effet devant l'entrée d'une librairie ou d'une boutique de disques, faute de savoir à l'avance ce qu'ils cherchent et d'être capables de répondre aux questions «cultivées » du libraire ou du disquaire. En fouillant dans les casiers, à la sortie du super-marché au contraire, ils peuvent repartir avec le Karajan ou le Malraux aperçus à la télévision.
Le cadre supérieur lecteur de L'Express qui n'a pas le temps de comparer les enregistrements nouveaux est heureux de se fier au hit-parade des disques classiques présenté par l'hebdomadaire; tout en entrant ainsi dans le système «maudit» des best-sellers, il pourra acquérir et pratiquer chez lui une œuvre de belle qualité. Troisième exemple qui montre bien l'intégration des média: tel hebdomadaire de télévision - et l'on connaît à la fois le succès de ces hebdomadaires et leur importance pour le choix des émissions par le public - présente à ses lecteurs non seulement une critique simplifiée des disques nouveaux, mais il indique la librairie - une coopérative sans but lucratif - où l'on peut commander par une simple lettre les chefs-d'œuvre désirés : dans le bourg rural le plus éloigné, le téléspectateur devenu amateur de musique peut faire venir les enregistrements sélectionnés par les meilleurs mélomanes.

Sans doute ces formes d'accès ne sont-elles pas satisfaisantes pour le musicien dont la pratique requiert des démarches plus personnelles comme autrefois, mais ce serait snobisme que de s'en moquer et de les tenir pour triviales, sans intérêt culturel. En Pologne, les messageries de la presse, l'entreprise nationale Ruch, disposent dans les quartiers et les villages de centaines de boutiques d'un genre spécial : on peut y acheter des journaux, des magazines, des livres, des reproductions, des disques; on peut aussi les consulter sur place, ou les emprunter comme auprès d'une bibliothèque, et ces boutiques, qui sont souvent situées au départ des trains, des autocars ou des autobus, comportent aussi un snack où l'on peut se restaurer légèrement et prendre un café. Ces librairies-cafés sont pleines d'hommes et de femmes ordinaires, vieux ou jeunes, qui passent là une demi-heure en allant faire leurs courses ou au retour du travail. C'est dans ces boutiques que les postes de télévision firent leur apparition quand ils n'étaient pas encore dans tous les foyers.

On voit ce qu'un tel réseau commercial peut offrir à l'époque des cassettes et des vidéo-disques, des imprimés bon marché et des imprimés chers. Certes, cette offre de produits industriels ne saurait remplacer les apprentissages vrais, longs et nécessaires, les contacts de personne à personne qu'ils supposent, l'expression et la pratique indispensables des groupes et des individus; mais le mariage des deux n'est pas impossible. Il est réalisé plus souvent qu'on ne le croit. Il est inévitable à terme : on n'a jamais vu aucune civilisation dédaigner les outils qu'elle s'est créés.

Source: Futuribles. Analyse - prévision - prospectives, n 17, septembre-octobre 1978, 618 p., p. 597-605 (dossier «Prospective du développement culturel »). Ont participé à ce numéro : Jean-François Collinet, Hugues de Varine, Pierre Belleville, Jean-François Barbier-Bouvet, Odile Timbart, Augustin Girard, Claude Fabrizio, Claude Mollard, Janine Cardona, Guy Poquet. Présentation de Geneviève Gentil et de Guy Poquet. 


\section{Pratiques et politiques}

Ce «point de vue », publié un an et demi après l'arrivée de Jack Lang au ministère de la Culture, pose la question de l'adaptation de la politique culturelle à la «nouvelle donne » induite par l'évolution des pratiques culturelles que le «Service des études et recherches » vient de mettre en lumière dans sa deuxième enquête*.

En une génération, la vie culturelle de la majorité des Français s'est profondément transformée. La plupart des ménages ont désormais équipé leur foyer de biens et d'appareils culturels qu'ils utilisent quotidiennement. Vingt ans de progrès technologique et le doublement du niveau de vie ont redistribué les cartes, mais l'intelligentsia n'en est guère consciente car ses pratiques, à elle, ont peu changé.

La plus grande part du temps libre est occupée par l'usage, relativement passif, de «machines culturelles », à base d'électronique, qui sont achetées sur le marché et dont les contenus sont indépendants des politiques culturelles publiques. Les pratiques individuelles à domicile, qui relèvent du commerce et de l'industrie, l'emportent de beaucoup sur la fréquentation collective de spectacles vivants qui, eux, sont de plus en plus subventionnés par les pouvoirs publics.

Soirées à la maison et industries culturelles contre sorties et salles de spectacles, que signifie cette apparente alternative pour les individus, pour les artistes, pour les institutions, pour les pouvoirs publics? La «culture» a pris de nouvelles formes, de nouvelles dimensions, et l'on est en droit de se demander par rapport à un tel changement de société ce qu'a fait la politique culturelle, si elle a tenu compte de la nouvelle « donne ».

Depuis 1959, date de la création d'un ministère des Affaires culturelles, le budget culturel a crû nettement plus que le budget général de l'État mais il s'est peu transformé dans sa structure, sauf en $1982^{*}$, où son montant et sa répartition ont été bouleversés. Il a régulièrement privilégié, comme dans tous les pays du monde, une hiérarchie d'institutions qui était parallèle à la hiérarchie sociale et inversement proportionnelle à l'étendue des publics touchés.

L'opéra est au sommet de la pyramide des subventions (plusieurs centaines de francs par spectateur, plusieurs milliers de francs pour le couple d'amateurs qui s'y rend cinq fois par an), mais ce sommet est bien étroit puisque $2 \%$ seulement des Français ont assisté dans l'année à un spectacle d'opéra. La subvention est

\section{2, année charnière}

1982, c'est l'année qui voit à la fois le quasi-doublement du budget du ministère de la Culture et le vote de la première loi de décentralisation, affirmant en son article premier que «les communes, départements et régions s'administrent librement ". C'est aussi l'année où, suivant l'exemple d'André Malraux en 1959, Jack Lang prend en personne la plume pour rédiger un nouveau décret fixant les missions de son ministère. Un texte qui, tout en reprenant à son compte l'objectif de démocratisation affiché par le décret fondateur de 1959, renoue avec l'ambition de « démocratie culturelle » définie lors du Front populaire (1936-1938) : affirmation du droit à l'expression de tous les citoyens, reconnaissance de la diversité des patrimoines, appel au « libre dialogue des cultures du monde ». A noter qu'alors, le Service des études et recherches est rattaché à la Direction du développement culturel qui, dans ces années-là, met précisément en œuvre plusieurs programmes de "diffusion sociale de la culture » destinés aux « milieux défavorisés ou en crise » que cite Augustin Girard.

égale pour le spectateur cadre supérieur et pour le spectateur ouvrier, mais le premier a statistiquement dix fois plus de chances de s'y rendre que le second. Dans les théâtres subventionnés, l'aide par fauteuil a été multipliée par cinq en francs constants, mais le public a stagné ou régressé, et la composition sociale est restée inchangée.

Au contraire, l'écart dans les chances d'accès n'est plus que de 1 à 2 lorsqu'il s'agit de la lecture, et de 1 à 1,2 pour le spectacle de télévision. Or ces deux activités, qui sont à la fois les plus prisées et les plus répandues dans le public, sont celles qui, jusqu'en 1981, recevaient le moins d'aide de l'État ${ }^{1}$. Doit-on dédaigner l'effet de la télévision quand on sait que $45 \%$ des Français regardent un spectacle de théâtre souvent ou de temps en temps, alors qu'ils ne sont que $10 \%$ à avoir fréquenté un spectacle en salle une fois dans l'année ? Même si l'on se garde d'oublier qu'il s'agit d'émotions très différentes ?

Voilà donc un financement qui est allé prioritairement à des institutions héritées du passé ou qui, même récentes (théâtres décentralisés, maisons de la culture), ne recrutent leur public que dans des catégories socioprofessionnelles déjà « cultivées » (le public est généralement composé de 50 à $65 \%$ d'étudiants et 
enseignants, 20 à $30 \%$ de cadres moyens ou supérieurs, 10 à $30 \%$ d'employés, 1 à $4 \%$ d'ouvriers et d'agriculteurs) et avec une hiérarchie géographique immuable (Paris, région parisienne, très grandes villes, villes moyennes, monde rural). Même si les institutions se sont raffermies et développées depuis une génération, même si elles sont efficaces et remplies de public, ce qui est souvent le cas, on peut se demander si elles suffiront jamais pour atteindre l'un des objectifs majeurs du financement public : la démocratisation* de la culture.

On peut certes considérer que la répartition traditionnelle de ces financements est bien naturelle : l'État n'aurait pas à intervenir dans les secteurs qui fonctionnent selon les lois du marché, et il devrait se borner à encourager les secteurs qui ne peuvent trouver par leur production propre des ressources suffisantes. Mais, si l'on tient compte du fait que les secteurs les plus aidés ne concernent qu'une faible part de la population et que la participation à leurs activités reste très élitaire, on peut se demander si la politique culturelle ne s'est pas trouvée jusqu'en 1982 en porte à faux : en dépit de ces objectifs égalitaires, elle a abouti à privilégier les privilégiés, elle est passée à côté des pratiques des milieux défavorisés ou en crise (milieux de travail, ruraux, jeunes), qui sont pourtant les plus nombreux. Dans le droit et budgétairement, tous les Français sont égaux devant la culture, mais il en va bien autrement dans la réalité.

Ne faudrait-il pas qu'une politique à moyen terme vise à remettre d'aplomb ce porte-à-faux ? Constatant que des mesures qui se voulaient égalitaires ont eu des effets pervers qui ont cumulé les facilités d'accès à la culture sur les mêmes catégories de population, ne doit-on pas imaginer des politiques explicitement inégalitaires qui interviennent en priorité en faveur des populations défavorisées (ruraux, travailleurs manuels)

\section{Les résultats de la deuxième enquête sur les pratiques culturelles}

Au moment où paraît cet article, le Service des études et recherches fait connaître les premiers résultats de la deuxième enquête (après celle de 1973) portant sur les pratiques culturelles de la population de quinze ans et plus résidant en France. Réalisée au cours de l'année 1981, cette enquête souligne que, malgré deux décennies de politique volontariste de l'État, l'implication croissante des collectivités territoriales - notamment des communes - et le militantisme de nombreux acteurs culturels, les pratiques restent avant tout liées à l'appartenance sociale ou générationnelle, aux logiques territoriales ou au niveau d'éducation. À la fin des "années Lang ", la troisième enquête - portant sur l'année 1989 - confirmera ce constat, suscitant l'incompréhension de nombreux professionnels de la culture qui s'attendaient à lire dans ses résultats, après une décennie d'efforts sans précédent de la part des pouvoirs publics, une augmentation généralisée des pratiques culturelles. et dans les milieux porteurs d'avenir: jeunes, enfants en milieu scolaire?

Ce n'est pas à une enquête par sondage, ni à l'analyse de flux financiers de fournir les mesures à inventer. La culture, dans ce qu'elle a de plus fécond, ne se rencontre guère au fil des pourcentages; ce qui fait son importance leur échappe : l'intensité des pratiques militantes ou associatives, le plaisir de l'amateur, et surtout la force vitale de la création. Le statisticien pose ses chiffres en forme de défi, puis il se tait. C'est au politique d'y répondre, c'est-à-dire l'élu, maire ou ministre, le serviteur de l'État et aussi le citoyen, la multiplicité des citoyens, chacun avec son pouvoir d'initiative, sa capacité de créer et la liberté de s'associer.

1. Mises à part les bibliothèques publiques qui touchent près d'un Français sur dix.

I Source: Le Monde, daté du 8 décembre 1982, p. 13 


\section{L'enjeu culturel}

«La démocratisation culturelle ratée, l'école et les grandes institutions dévaluées, les médias incontrôlés » : le constat dressé est sévère. À cette analyse sans concession, l'auteur ajoute un plaidoyer en faveur d'une "conception démocratique de la culture " qui prenne davantage en compte la demande des populations et privilégie une politique «socioculturelle»plurielle et décentralisée.

Il peut paraître surprenant - mais il est significatif - que, parmi les enjeux de la fin du siècle, on ait songé à inclure la culture aux côtés de l'économie, de la biologie ou du tiers-monde. Il y a trente ans, nul ne l'aurait fait.

Pourquoi donc la culture, vieille comme le monde, domaine par excellence du for intérieur, trésor des happy few, vient-elle prendre place parmi les priorités publiques de la société au cours des quinze prochaines années?

Serait-ce parce que la société s'aperçoit peu à peu que sa crise est plus culturelle qu'économique? Que sa dépression d'aujourd'hui est subjective, comme toutes les déprimes? Qu'elle est une affaire d'espoir, de conscience de l'avenir, de sens dans la vie, c'està-dire de culture ? Est-ce parce que la nation, en transition entre deux âges, se tourne vers un de ses ressorts les plus profonds, c'est-à-dire sa culture, pour se remettre debout?

\section{UNE SOCIÉTÉ SANS AVENIR}

Le Français n'a jamais eu la vie aussi bonne, et le voilà pourtant morose, pessimiste, disent les sondages, il a peur des lendemains. Il vit beaucoup mieux que ses parents, et il ne sait plus quel sens a sa vie. Les jeunes se déclarent «sans avenir», et le prouvent en vivant au jour le jour. Ceux d'entre eux qui réussissent le mieux déclarent ne plus rechercher à rendre le monde plus vivable autour d'eux, ils espèrent seulement « faire leur trou » dans le monde tel qu'il est. Pas de projet collectif. «Le pire désastre qui puisse menacer un peuple», disait Pierre Emmanuel, «n'est pas l'anéantissement militaire, c'est l'indifférence à la forme de son avenir ». C'est ce désastre culturel qu'on constate chez beaucoup de jeunes.

Or, l'avenir de chacun n'est pas une affaire individuelle, il n'existe qu'à travers la société, à condition qu'elle soit rassemblée autour d'un projet explicite, de choix partagés. Ce projet commun, qui a fait les grandes civilisations du passé, a toujours été le produit d'une culture. Il n'est ni technique, ni économique, mais relève de l'idée que l'homme se fait de lui-même [...] Or, la modernisation fait peur aux Fran- çais plus qu'elle ne les mobilise, ils ne croient vraiment ni à la science ni au progrès, et quant à la formation, objectif naguère largement partagé par les familles, on ne croit plus guère à son efficacité. Le «Laisse béton» de 1979 a été remplacé en 1985 par «Va faire un stage! ». Notre société, à la fois hypercomplexe, émiettée et contrainte à changer très vite, ne se suffit plus du technique et requiert le ciment moral que constitue une culture commune. Sans elle, le pays se désagrège en cellules très différenciées, performantes parfois, mais finalement impuissantes.

À tous les moments décisifs, où la conscience nationale a cherché instinctivement les ressorts capables de dresser la nation debout vers un avenir, elle s'est tournée vers la culture comme vers sa ressource profonde : qu'il s'agisse de forger la III $^{\mathrm{e}}$ République dans les années 1880 grâce à la première démocratisation culturelle - l'enseignement -, de refaire la République dans la Résistance et l'après-guerre en réconciliant le peuple et la culture, de maîtriser la croissance dans les années soixante en étendant au culturel la planification du développement, ou enfin de sortir de la crise dans les années quatre-vingt en dépassant l'économicisme, le recours au culturel a émergé comme un besoin [...].

\section{IDENTITÉ CULTURELLE}

\section{ET SENS DE L'AVENIR}

Si le recours au culturel émerge comme un enjeu, c'est qu'un peuple, pas plus qu'un homme, ne peut se passer d'identité. Il ne peut vivre sans éprouver le sentiment de valoir quelque chose, sans avoir une certaine idée de lui-même, sans un vouloir-être bien à lui. Culturelle, cette identité l'est pleinement, à la fois parce qu'elle est une mémoire et un appui sur le passé, mais surtout, et bien plus, parce qu'elle est une volonté de devenir et une adaptation créatrice, sui generis, aux défis contemporains. Il n'est donc pas d'identité culturelle sans construction d'un avenir, pas plus qu'on ne construit un avenir sans identité culturelle. Avenir et culture sont liés.

[...] Aujourd'hui, le temps s'est rétréci, miniaturisé - comme l'espace - grâce à la télévision et aux communications de toutes sortes. Il s'est atomisé en 
instants juxtaposés et non hiérarchisés, et si l'individu n'a ni culture ni sens du temps pour organiser les miettes de sa vie, il en perd le sens [...] La «crise» est culturelle, bien plus qu'énergétique, technologique ou monétaire. Le niveau de vie, la richesse nationale sont beaucoup plus élevés aujourd'hui qu'aux époques sans « crise » [...] Mais, ce qui manque, c'est la capacité de discerner des fins communes, des objectifs partagés, un avenir qui ait un sens.

[...] Avenir, espoir, identité, ces grands mots ne sont pas agités ici par a priori moral, mais parce qu'on les redécouvre aujourd'hui comme des «must » expérimentaux de la vie collective. Et ce que l'on constate ainsi objectivement, ce que l'on redécouvre empiriquement, ce sont des concepts éthiques, comme si l'espèce humaine ne pouvait pas se passer de choses aussi concrètes que de valoir quelque chose, d'être porteur d'un enjeu spécifique, le besoin irrépressible de donner un « sens » - à la fois orientation et signification à la vie qu'il faut mener. Or, ce besoin de sens, d'identité et d'avenir est affaire de culture, et c'est en cela que la culture est un enjeu des prochaines années.

[Suivent plusieurs pages dans lesquelles l'auteur développe son analyse à travers quatre paragraphes aux titres sans ambiguïté: "L'échec relatif des institutions culturelles »; "Le ratage de l'École »; "L'occasion perdue des médias »; "Le cheval de paille des libertés et le cheval de Troie du marché», avant de conclure]

Ainsi, en 1985, après vingt-cinq ans de politique culturelle délibérée, d'une croissance budgétaire inégalée, d'efforts considérables des militants, des élus, des administrateurs, ceux-ci se retrouvent sous le coup d'une triple désillusion : la démocratisation culturelle ratée, l'école et les grandes institutions dévaluées, les médias incontrôlés [...] Or, en même temps que les pensers anciens et les moyens nouveaux se révélaient infructueux, les acteurs culturels se retrouvaient devant des Français changés au plus profond de leur mentalité, sinon de leurs valeurs, surtout parmi les moins de trente-cinq ans.

[...] Voilà donc des jeunes Français plus ouverts à la culture que leurs pères et plus demandeurs. Or, s'offre à eux un temps de loisir qui se sera multiplié par deux entre 1900 et 1995 - tandis que le temps de travail se sera divisé par deux dans une vie allongée de vingtcinq ans. C'est une sorte de seconde vie qu'offre l'accroissement de la productivité au cours du $\mathrm{XX}^{\mathrm{e}}$ siècle. Il y a là un fait brut capital dont la société n'a pas pris pleinement conscience, et l'enjeu de la politique culturelle dans les dix années à venir est de savoir si on laissera ce loisir devenir simplement l'oisiveté, ou si on utilisera cette seconde vie pour rendre l'homme plus homme, cultiver en lui le meilleur et développer cette culture qui est la noblesse du monde [...].

\section{QUELLE POLITIQUE PUBLIQUE}

\section{DE LA CULTURE?}

Il est hautement improbable qu'il n'en existe plus : outre qu'on ne raye pas d'un trait de plume l'activité de quelques milliers d'hommes que Malraux a mis à la tâche, il y a surtout quelques fonctions «nationales » - je préfère ce mot à « régaliennes » - qui ne peuvent être assumées par d'autres que les pouvoirs publics : la conservation-mise en valeur du patrimoine [...] ; la création [...] ; l'éducation artistique. À ces trois fonctions classiques de l'État, tendent à s'ajouter, partout en Europe, des formes nouvelles et discrètes de tutelle sur les industries de la culture, et notamment sur la plus puissante d'entre elles, la télévision [...] Si ces quatre fonctions sont nationales, cela ne veut pas dire - tout au contraire - qu'elles doivent être traitées par l'État de façon napoléonienne [...] La politique culturelle de la fin du siècle, si elle veut répondre aux défis de la société, et trouver ainsi une légitimité qui lui manque encore, doit être débureaucratisée et rendue à des pratiques démocratiques de concertation. Louis XIV est mort. Dans une société marquée par la pluralité des modèles culturels, il importe qu'à l'instar de nombreux pays étrangers, des conseils culturels existent à tous les niveaux - communal, départemental, régional et national - et que des responsabilités vraies leur soient données, en termes de définition de politiques et d'élaboration budgétaire.

Relève enfin de la responsabilité nationale l'objectif de réduction des inégalités culturelles géographiques d'abord, sociales aussi. L'équipement et les ressources varient beaucoup trop entre les régions, et Paris absorbe une part scandaleusement forte des dépenses nationales [...] Or, le rééquilibrage du territoire est une question de santé pour l'identité culturelle du pays. Parallèlement, les inégalités sociales d'accès à la culture [...] doivent être systématiquement pourchassées - même sans illusion -, ne seraitce que parce que sans redistribution spécifique et inégalitaire, les subventions égalitaires vont naturellement d'abord dans la poche de ceux qui sont déjà cultivés, informés et pratiquants. C'est une tâche nationale que de lutter contre la variante culturelle de la loi naturelle selon laquelle l'argent va aux riches.

\section{RÉANIMER LA SOCIÉTÉ CIVILE}

Il n'était pas possible de ne pas rappeler ces fonctions nationales classiques, mais il fallait aussi esquisser des modalités plus modernes pour leur gestion, indispensables pour combattre les trois grandes maladies récurrentes de la politique culturelle : l'élitisme, qui est une tendance naturelle et fatale dans la vie artistique, la passivité des citoyens et la bureaucratie sans cesse renaissante. Si ces modalités modernes de gestion démocratique sont mises en place [...], les choix 
culturels traditionnels seront partagés par tout le corps social, ce qui est nécessaire pour donner sa pleine légitimité à la dépense culturelle publique.

Mais ce partage ne sera vécu par la majorité de la population que si l'on associe à ces objectifs traditionnels un autre objectif que nous intitulerons la « culture pour tous », ou plutôt les « cultures de tous », avec des modalités d'action qui soient en phase avec les mentalités nouvelles que nous avons repérées plus haut. Si l'on admet l'idée que l'enjeu culturel n'est pas seulement le développement de la vie artistique, mais aussi la reconstruction d'une identité culturelle pour chacun et pour la nation, condition d'un avenir, d'un projet humain, d'une civilisation nouvelle à faire émerger, il faut aider la vie culturelle telle qu'elle est vécue par la multiplicité des citoyens sur tout le territoire, et non pas telle qu'elle est conçue par l'intelligentsia parisienne [...] Il ne s'agit pas seulement de transformer une gestion parisienne en une gestion dans les régions où ne tarderont pas à s'opérer des recentralisations sur des notables et des bureaucraties locales [...]; il faut surtout favoriser et accueillir la demande locale, dans son foisonnement hétéroclite. L'attention aux initiatives petites et non institutionnalisées, dans une société de libre-service où les gens participent sans adhérer [...], l'attention aux entreprises libres qui se veulent indépendantes des collectivités publiques [...], l'attention à toutes les formes de culture interstitielle liées à la vie quotidienne de l'habitat, du commerce, du travail et des transports [...] sera préférée au subventionnement exclusif des institutions lourdes.

\section{RELANCER L'ACTION SOCIOCULTURELLE}

L'important est de donner aux gens, là où ils travaillent et où ils vivent, la culture de ce qu'ils font, de ce qu'ils sont, de là où ils sont [...] Ce qui importe, ce n'est pas la maison de «la» culture, mais la maison de « ma » culture. Malraux s'était trompé : ce n'est pas faire connaître Cézanne ou l'art des grottes en Inde qui fait tenir les gens debout, qui les fait découvrir leur identité, ce qu'ils valent, mais bien plutôt leur faire sentir ce qui a valeur culturelle dans leur propre travail et dans leur propre environnement [...] Valoriser l'homme dans son travail est peut-être plus important, plus facile et moins cher que de lui apporter l'opéra.

[...] La politique socioculturelle de la fin du siècle sera donc et volontariste et décentralisée, affichant des valeurs mais pas de projet unique, requérant une pluralité, une multiplicité non finie d'initiatives et de petits projets, aussi nombreux que les cantons, les communes et les quartiers. Ils ne seront pas organisés depuis la capitale. Point de «centre d'action culturelle» type, défini par des textes élaborés à Paris, mais un tissu vivant, informé et informateur, d'équipes créatrices, mobiles, sans doute éphémères, mais renaissant sans cesse sous de nouvelles formes, avec des expressions diverses. L'État central ne s'en désintéressera pas, il les fera connaître et se connaître entre elles par une politique d'information, il veillera à ce que des maladies passagères ne les détruisent pas, mais ces équipes n'auront pas à attendre la reconnaissance de Paris pour exister. Le financement public se fera à travers les comités de développement culturel départementaux ou régionaux, responsables de l'instruction des dossiers et de l'évaluation des résultats.

\section{LA DÉMOCRATIE CULTURELLE}

Voilà donc des esquisses de politiques culturelles, alors qu'il s'agissait de présenter ici concrètement des enjeux. C'est qu'en matière de culture, l'enjeu est autant dans les processus que dans les œuvres, dans les méthodes d'action et les attitudes que dans les objectifs et les contenus.

[...] Désormais, il n'est plus possible de proposer une culture unique, qui détiendrait une vérité. Le temps est révolu des grandes cultures cosmogoniques, où l'art figurait l'organisation du monde et rendait visibles ses lois et ses sagesses. La culture d'aujourd'hui est plurielle, et le problème de l'action culturelle publique est de transformer ce pluralisme en valeur collective. Libre à chacun de trouver un sens à sa vie, de se constituer une éthique ou une esthétique, mais la politique culturelle, dans sa visée démocratique, est là pour l'aider dans sa démarche, quelle qu'elle soit. La politique culturelle n'a pas pour objet d'accoucher la société d'un monde défini comme souhaitable, mais de permettre à tous, quels que soient leurs modèles de vie, de bâtir des réponses humaines aux menaces du prévisible et de l'imprévisible.

Telle est la conception démocratique de la culture. Si la démocratie est un ensemble de régulations pragmatiques qui garantissent à toutes les cultures et aux cultures de tous de pouvoir se développer, le respect réciproque de ces cultures devient précisément la culture. La culture ainsi entendue devient un absolu - absolu pluriel - et une finalité de la démocratie.

Mais elle est à son tour une condition de la démocratie. Il ne peut y avoir maîtrise des libertés individuelles, par leur respect réciproque, que s'il y a chez tous un apprentissage de celles-ci. Ce qui n'est pas de l'ordre du savoir, mais de la culture.

Culture et démocratie semblent ainsi pragmatiquement liées, l'une étant à l'autre son instrument nécessaire, en même temps qu'elle est sa finalité. Dans la démocratie culturelle, la fin et les moyens enfin se rejoignent.

Source: texte paru dans Les Enjeux de la fin du siècle, ouvrage dirigé par Antoine de Tarlé, présentation de René Rémond, Paris, Desclée de Brouwer, 1986, p. 69-91 [coll. « Temps et contretemps 3 »; contributions de Michel Albert, Jean Bernard, Bernard Cathelat, Augustin Girard, René Lenoir, André de Peretti, Albert du Roy, Jean-Louis Schlegel, Raymond Soubie, Antoine de Tarlé]. 


\section{Trente ans après}

Rédigé au moment où Augustin Girard s'apprête à quitter le service qu'il a créé trois décennies auparavant, ce texte est autant un rapport d'activité qu'une forme de "testament professionnel ». S'il souligne le "problème de temporalité » existant entre le temps du chercheur et celui du décideur, il insiste sur la nouvelle "ardente obligation» que représente l'évaluation pour toute politique publique et appelle de ses vœux une "problématique nouvelle » à même de répondre aux enjeux culturels de la fin du XX siècle.

Si le présent rapport d'activité porte sur trois années, il coïncide avec le trentenaire du Département, et avec le renouvellement du responsable du Département. Ces deux faits incitent et autorisent peut-être ce dernier à s'interroger, à titre personnel désormais, sur le chemin qu'il semble aujourd'hui nécessaire de parcourir.

\section{L'IMPÉRATIF D'UN MEILLEUR PARTAGE DES RÉSULTATS}

Le premier impératif est de faire mieux partager les résultats de la recherche. Ce partage comprend deux temps: d'abord, la publication des travaux, ensuite, la réception par les destinataires. [...]

Cette valorisation première est toujours menacée, déjà par le chercheur, s'il n'intègre pas le souci du partage de ses découvertes, puis par l'administration, qui ne comprend pas que la vulgarisation requiert des talents exceptionnels, qui n'existent pas chez elle, et donc l'existence de vulgarisateurs permanents spécifiques.

Les publications $[\ldots]$ ne suffisent pourtant pas pour que les résultats des travaux soient lus et utilisés par les décideurs [...] On s'aperçoit qu'elles ont «informé » au sens fort, c'est-à-dire proposé des concepts organisateurs, des chiffres, des états des lieux, des évaluations à un milieu bigarré et osmotique de deux à trois milliers d'acteurs du domaine culturel [...], plutôt que provoqué, dans le délai minimum, des stratégies nouvelles dans les directions concernées. On touche là à un problème structurel, qui n'est pas propre au ministère de la Culture, ni même à la haute administration dans son ensemble et a fortiori à la sphère politique. Il y a paradoxalement comme une antinomie entre l'aide à la décision et la décision. Cette antinomie tient essentiellement à un phénomène de temporalité. Les commandes d'étude naissent généralement de situations de crise, mais cette crise, le ministre et le directeur s'emploient aussitôt à la gérer dans l'immédiat, le ministre avec son instinct politique, le directeur avec sa panoplie de mesures budgétaires [...], tandis que le chercheur vise à cerner les fondements de la crise, à mettre en place une méthodologie spécifique pour l'observation - or, toute étude est un prototype - et finit après dix-huit mois par découvrir en profondeur des voies durables de sortie de crise, touchant naturellement le moyen et le long terme. Si la crise dure encore au moment de la sortie de l'étude, l'étude est utile pour que l'appareil de décision définisse déjà quelques mesures pratiques [...].

La temporalité de la planification à moyen terme convient beaucoup mieux à l'utilisation des études. Et de fait, c'est la demande du Commissariat général du Plan, avec ses temps forts tous les cinq ans, qui a été la meilleure occasion d'interroger les études et recherches pour faire surgir des stratégies culturelles nouvelles. Le souci de planification à moyen terme est resté généralement faible chez les dirigeants du ministère. Fort rares ont été, en trente ans, les réunions de directeurs ou les séminaires de cabinet qui ont négligé les urgences pendant une journée pour parler objectifs généraux, priorités, grands équilibres, révision de fond des voies et moyens. Il manque un lieu auprès du ministère, où s'effectuerait ce travail permanent. Il n'existe pas non plus auprès du Parlement, dont les débats restent étonnamment pauvres et peu suivis [...].

\section{AFFICHER UN OBJECTIF FÉDÉRATEUR : L'ÉVALUATION}

La planification étant passée de mode [...], la France a découvert aux États-Unis le concept plus pragmatique, moins rationalisateur et très riche, de l'«évaluation ». Qu'il s'agisse d'évaluation ex post (après un programme), instantanée (états des lieux) ou ex ante (avant un programme), qu'il s'agisse d'opérations ponctuelles, de politiques sectorielles ou de stratégies culturelles globales au niveau local ou au niveau national, la plupart des études socio-économiques, nourries en amont par les résultats de la recherche, s'insèrent naturellement dans ces processus. Les méthodes varient selon les différents types d'évaluation recherchés, mais elles sont déjà rodées. 
En créant auprès de lui un comité scientifique de l'évaluation, le premier ministre Rocard a institué une sorte de comité des méthodes pour cette «ardente obligation » nouvelle, qu'il souhaitait voir se diffuser dans l'État [...].

\section{FAIre ÉMERGER \\ UNE PROBLÉMATIQUE NOUVELLE}

Les méthodes de l'évaluation des politiques publiques ont toutes en commun de requérir une élucidation explicite des objectifs. Sans objectifs clairs, pas de critères d'évaluation. Or, en matière de culture, ces objectifs sont flous : quelles formes d'art souhaitet-on privilégier et pourquoi ? Quels publics vise-t-on? Quels processus d'apprentissage entend-on enclencher? Quelles fonctions - création, diffusion, sensibilisation, formation, conservation du patrimoine vise-t-on pour telle ou telle opération, pour telle ou telle période donnée, pour tel ou tel niveau géographique?

Or, tous ces objectifs « instrumentaux » ne peuvent pas ne pas se référer à une problématique culturelle d'ensemble bien explicitée. Implicites, ces objectifs l'ont été, comme le rappellent les décrets d'attributions constitutifs des ministères successifs : «l'accès du plus grand nombre aux œuvres de l'art et de l'esprit », «le soutien à la création et à sa liberté », « la conservation du patrimoine». Mais ces missions restent aussi vagues que l' ancien « informer, distraire et cultiver » de la radio-télévision française.

En amont des objectifs, il y a des finalités générales qu'il faut expliciter. En Suède, par exemple, ces finalités sont clairement sociales. En France, on a plutôt fonctionné sur la doctrine de la « démocratisation de la culture », par homothétie avec la démocratisation de l'éducation, ou sur celle du « développement culturel », par analogie avec le développement économique et le développement social. Or, l'accès à l'art et à la culture ne fonctionne pas comme l'accès à l'éducation, laquelle est obligatoire et nécessairement universaliste. Le développement culturel, à la fois de l'individu et de la société, ne correspond pas à une demande très forte, comme par exemple le développement des prestations sociales. Ces deux idéologies de la démocratisation et du développement, héritières du Front populaire et de la Résistance par l'intermédiaire des mouvements d'éducation populaire, pour la première, et de la croyance au développement dans les années soixante, pour la seconde, ont été quelque peu démenties par l'expérience des trente dernières années. La technologie ayant changé les moyens d'accès aux œuvres, et même les formes artistiques, ayant mêlé de façon inextricable simple divertissement et culture, bouleversé enfin l'ampleur et l'emploi du temps de loisir, la fin du siècle se caractérise par une large confusion des valeurs et des modes de pratiques, bousculant les institutions et les hiérarchies établies ainsi que les modes d'adhésion de la population qu'elles entraînaient. La consommation individuelle de masse ayant multiplié les libertés, les légitimités et les occasions d'accès d'une large population de tous âges, le monde de la culture est devenu un vaste selfservice où les valeurs ne disparaissent pas peut-être, mais sont sans doute plus difficiles à trouver.

Au nom de quoi, devant ces formes nouvelles d'accès et de création, les pouvoirs publics seraient-ils sommés d'intervenir? Comment pourraient s'articuler des finalités, à redéfinir, avec des objectifs instrumentaux, à afficher, et des modalités de travail, à réinventer? C'est cet ensemble que nous appelons une problématique nouvelle du développement culturel et que nous estimons une priorité du ministère en cette fin de siècle. Il ne saurait en faire l'économie s'il veut avancer clairement sur la voie de l'évaluation et hiérarchiser les stratégies nouvelles de développement qui en découleront.

La méthode pour élaborer cette problématique et réinventer en continu n'est pas de convoquer dans quelque raout spectaculaire le Gotha de l'intelligentsia parisienne et de laisser chacun développer son obsession personnelle du moment. Il faut, par un travail étalé sur plus d'un an, et chaque année repris, confronter de façon disciplinée la frustration, le scandale, l'étonnement des artistes, des philosophes, des essayistes, des anthropologues ou des hommes de religion, d'une part, avec les observations à plat que des praticiens, professionnels et élus, qui ont exploré les alternatives de l'action, des sociologues, des économistes, des technologues et des historiens peuvent pragmatiquement avancer sur les pratiques et les goûts, les enchaînements industriels et commerciaux, les priorités sociales d'autre part. La vision nouvelle n'émergera pas des pirouettes polémiques naturellement chères aux intellectuels, mais d'un travail empirique au sens où tout travail scientifique suppose de confronter dans l'obstination des hypothèses successives à des réalités. Il serait important que le Département des études et de la prospective contribue à cette vaste et patiente tâche, par ses crédits, avec son réseau, et grâce aux femmes et aux hommes dont la passion est ici présentée.

Source: initialement paru sous forme d'“avant-propos » au Rap-
port d'activité du DEP, 1989-1992, Paris, Ministère de la Culture,
DEP [1993], ce texte a été repris, sous le titre Trente ans après,
dans l'ouvrage intitulé Trente ans d'études au service de la vie
culturelle publié en juillet 1993, quelques mois après la table ronde
organisée, le 8 mars 1993, à l'occasion du départ à la retraite d'Au-
gustin Girard; figurant p. 112-119, il constitue l'annexe 2 de ce
document - non commercialisé - réalisé avec le concours du
ministère de la Culture et de la Francophonie et de la Documenta-
tion française (document disponible auprès du Comité d'histoire). 


\title{
Une dynamique pour l'avenir
}

\author{
8 mars 1993 : la manifestation organisée à l'occasion de son départ à la retraite permet à Augustin \\ Girard de rendre hommage aux «camarades de combat» qui l'ont accompagné au cours des trente \\ années qu'il a passées à la tête de son service. C'est aussi le moment de souligner l'évolution tren- \\ tenaire de la société et de revenir sur les conditions d'exercice de la recherche au sein d'une admi- \\ nistration comme sur quelques convictions.
}

[...] Les idées avancées par le Département dans les années 1960, qui étaient issues des mouvements de l'Éducation populaire et de l'idéologie de la planification, de la croyance en un possible progrès économique et social, ont été bouleversées par la technologie. C'est aujourd'hui la technique qui guide le monde, qui guide les armes, qui guide les sociétés par la communication, qui fait la force toute-puissante des marchands. Or, la technologie a beaucoup changé depuis 1960, depuis la création du ministère.

Depuis trente ans, les moyens d'accès aux æuvres [...] et même les formes artistiques elles-mêmes, les formes de la création ont été changées par la technique. C'est la technique qui a mêlé de façon inextricable le simple divertissement, l'entertainment dont on nous rebat les oreilles, et les œuvres de culture. La technique a bouleversé l'ampleur de l'emploi du temps et les moyens de le remplir, ce temps de loisir que Joffre Dumazedier avait espéré valoriser comme un temps de culture et de développement. Et la fin de notre siècle, les années qui passent en accéléré devant nos yeux, se caractérisent par une large confusion des valeurs et des modes de pratiques. Cette confusion bouscule les institutions et les hiérarchies, ainsi que les modes d'adhésion des individus, et les fidélités qu'avaient naguère les populations. Paul Yonnet parle d'une «consommation individuelle de masse »- le terme est excellent - qui multiplie les libertés, certes, les légitimités aussi, et les occasions d'accès d'une population de toutes classes et de tous âges, au-delà des discriminations classiques. Le monde de la culture est devenu un vaste self-service, comme l'est le monde politique, comme l'est aussi le monde religieux, où les valeurs, sans disparaître peut-être, sont de plus en plus difficiles à repérer.

Alors on peut se demander, devant des formes nouvelles de création, devant des formes nouvelles d'accès, on doit se demander au nom de quoi les pouvoirs publics seraient désormais sommés d'intervenir. Je crains que la question ne se pose très vite, dès les arbitrages budgétaires qui sont proches.

[...] Je ne pense pas que le ministère puisse faire l'économie de cette réflexion, d'autant plus qu'il veut avancer clairement sur la voie de l'évaluation et donc établir des critères. Or, pas de critères sans finalités, sans objectifs explicites, et il faudra bien hiérarchiser à nouveau les stratégies de développement que va mener la puissance publique, et notamment l'État.

[...] Il faut savoir que toute étude est un prototype original, où la probabilité d'échouer est plus grande que la probabilité de réussir. Et que, loin d'être une routine administrative, l'administration de la recherche - car nous sommes tous mi-chercheurs, miadministrateurs de recherche - est un exercice de corde raide. Quand nous gérons des crédits d'État, dont nous sommes comptables, nous avons parfois la peur au ventre, et partager la peur dans un combat, c'est aussi ce qui soude une équipe. Le combat était d'abord dans la lutte contre les idées préconçues et les clichés erronés. Mais le combat était aussi une lutte contre des structures administratives incroyablement vétustes [...] gravement inadaptées à l'invention, et qui semblent avoir principalement pour objet de mettre des bâtons dans les roues d'un bout à l'autre du travail, depuis la conception des travaux jusqu'à la publication et la promotion des résultats. Il nous fallait «utiliser» ces structures, mais avec beaucoup de ruse et parfois de l'audace, parfois même les contourner jusqu' aux limites de la légalité. Sans jamais cependant tromper, je le souligne ici, le contrôleur financier [...].

[Cette manifestation] est donc pour moi l'occasion presque solennelle, si je puis dire, d'exprimer ma reconnaissance à mes camarades de combat pour toutes ces heures anxieuses et toutes ces heures joyeuses de succès vécues en commun. On riait souvent, et les sourires de connivence que nous échangions parfois aux détours d'un couloir étaient délicieux.

[...] Je remercierai dans le même mouvement tous ceux qui ont formé la première « doctrine », bien que je n'aime pas ce mot qui évoque des dogmes, je dirai plutôt la première éthique professionnelle du Département. En tout premier, je citerai Bernard Anthonioz [...] C'est à lui que je dois cette farce originelle de m'avoir fait venir à la première Commission culturelle 
du Plan, alors que ma seule « compétence » était mon jeune âge. Mais c'est surtout lui qui a donné le modèle de ce que peut être la relation entre l'État et l'artiste vivant, c'est-à-dire une relation faite tout entière de respect et d'humilité fraternelle.

Une autre grande source d'inspiration pour le Service a été «Peuple et Culture». Il y avait Joseph Rovan, toujours si brillant; il y avait surtout Joffre Dumazedier, qui a été pour moi un maître de recherche au sens plein du terme [...] Il avait inventé ce qu'on appelle aujourd'hui, un peu prétentieusement, le paradigme du «développement culturel», avec tous les concepts qu'il décline. C'est lui aussi, et «Peuple et Culture », qui m'ont transmis l'héritage du Conseil national de la Résistance en matière culturelle, que je vous conseille de relire, et aussi les très beaux espoirs qu'avaient formulés, écrits et commencé de mettre en œuvre Jean Zay et Léo Lagrange. Nous n'ignorons pas l'héritage, encore plus ancien, de Marc Sangnier et du «Sillon », où j' ai redécouvert par hasard le militantisme de mon propre père, dans les années 1900 [...] Il y avait une vie associative extrêmement riche à cette époque, qui nous a beaucoup nourris. Il y avait «La Vie nouvelle», avec Jean Lestavel, «Citoyens $60 »$, avec Jacques Delors [...] Il y avait Pierre Belleville $[\ldots]$, avec les Centres de culture ouvrière, où j'ai travaillé avec un jeune inspecteur des finances qui allait expliquer l'économie le soir dans des usines de banlieue et qui s'appelait Michel Rocard. Dans tout ce foisonnement associatif, il régnait encore la personnalité d'Emmanuel Mounier, du personnalisme, de la revue Esprit, que conduisait Jean-Marie Domenach, et qui est resté, quel que soit le renouveau, une revue qui nous importe beaucoup et qui nous forme.

Je dis cela pour bien faire sentir à ceux qui prennent la relève, en pleine « ère du vide », comme on dit, et de la «consommation individuelle de masse », que la venue au monde du Service s'est faite en une époque forte d'espoir et extrêmement volontariste. Leur tâche à eux sera d'autant plus difficile et d'autant plus nécessaire que cette ère-ci est gravement incertaine.

[...] Notre réunion [...] s'inscrit dans une histoire et dans un esprit qui n'est peut-être pas autre que ce mystérieux et toujours présent «fil de l'esprit» qui passe quelque part entre nous ou tout proche de nous [...] Et, à force d'avoir avec nous tous ces amis que parcourait le fil de l'esprit, nous avons senti se tresser une corde, et c'est cette corde qui nous a soutenus contre l'indifférence des puissants. Elle nous soutiendra et nous soutient toujours. Beaucoup d'entre vous, j'en suis sûr, [...] auraient parlé ce langage que je viens de tenir, qui est le seul langage de la culture qui nous intéresse, tous comptes faits: «Une culture qui ne serait pas une insurrection permanente de l'esprit ne serait qu'une industrie de plus», a dit Domenach.

\section{Quelques «camarades de combat »}

Bernard Anthonioz (1921-1994), résistant, éditeur, ami d'André Malraux, a participé à la création du ministère des Affaires culturelles en 1959. Chef du Service de la création artistique de 1962 à 1979, il est l'un des principaux artisans de la politique nationale menée en faveur de l'art contemporain.

Pierre Belleville, militant de l'éducation populaire, promoteur des "Centres de culture ouvrière ", auteur du rapport "Pour la culture dans l'entreprise» remis en 1982 à Jack Lang, ministre de la Culture.

Yves Brunsvick (1921-1999), ministre plénipotentiaire, secrétaire général de la Commission française pour l'UNESCO, président d'honneur du Conseil du bureau international d'éducation.

Jean-Louis Crémieux-Brilhac (né en 1917), résistant, directeur de la revue L'Expansion de la recherche scientifique, cofondateur et premier directeur de la Documentation française.

Joffre Dumazedier (1915-2002) : voir page 3 (encadré « La civilisation du loisir »).

Pierre Moinot (1920-2007), collaborateur d'André Malraux dès 1959, démissionne en 1962 en raison de la faiblesse des crédits alloués à la politique culturelle. Rappelé par Malraux en 1966, il est jusqu'en 1969 directeur général des arts et des lettres puis prend, dans les années 1970 et 1980, une part active à la politique audiovisuelle. Également romancier et scénariste, il a été élu à l'Académie française en 1982.

Joseph Rovan (1918-2004), militant de l'éducation populaire, cofondateur, avec Joffre Dumazedier, de «Peuple et Culture».

Je voudrais terminer par une dernière citation [...] c'est celle d'un ministre de la Culture camerounais qui a dit ceci, dans cette salle : «Pour nous, Africains, la culture est inséparable de la vie réelle du peuple: c'est elle qui définit sa dignité, son enracinement historique et son dynamisme face à l'avenir. » Alors, dynamisme face à l'avenir [...] je vous remercie d'avoir été si étonnamment nombreux ce soir à témoigner à la relève de votre conviction que la culture est à la fois le moyen et la fin ultime du développement de nos sociétés, ainsi que la dignité de ce que Robert Antelme a appelé, au retour de Dachau, d'un drôle de nom : «l'espèce humaine ».

Source: ce texte figure en conclusion (p. 89-99) de l'ouvrage intitulé Trente ans d'études au service de la vie culturelle publié en juillet 1993, quelques mois après la table ronde organisée, le 8 mars 1993, à l'occasion du départ à la retraite d'Augustin Girard ; non commercialisé, cet ouvrage a été réalisé avec le concours du ministère de la Culture et de la Francophonie et de la Documentation française (document disponible auprès du Comité d'histoire). 


\title{
Un cas de partenariat \\ entre administration et recherche scientifique : la socio-économie de la culture
}

\author{
Dans les années 1960, il n'est pas si fréquent, au sein de l'administration de l'État, qu'un ministère \\ compte un "service des études et recherches». Il est encore plus rare que la création de ce service \\ joue un rôle déterminant dans l'éclosion et l'essor d'une discipline nouvelle, en l'occurrence la \\ socio-économie de la culture. Dans ce texte, Augustin Girard revient sur les conditions nécessaires \\ pour qu'un tel partenariat entre l'administration et le monde de la recherche se révèle fécond.
}

Dès sa création en 1963 (par Jacques Delors, du Commissariat général du Plan), [...] le « Service des études et recherches » a eu pour partenaires des laboratoires du CNRS et de l'Université : Michel Crozier, Pierre Bourdieu, Robert Francès, Paul-Henry Chombart de Lauwe, Joffre Dumazedier, entre autres, puis Raymonde Moulin et Pierre-Michel Menger, Erhard Friedberg et Philippe Urfalino, Antoine Hennion et le Centre de sociologie de l'innovation. À partir de 1974, ce partenariat a reçu l'appui de la Délégation générale à la recherche scientifique et technique [...] tandis que le ministère de la Culture commençait à être alimenté régulièrement par une enveloppe spécifique dans le « budget civil de recherche et développement » (BCRD) [...] Cette expérience autorise peut-être à expliciter les conditions d'un partenariat volontariste entre un service d'études socio-économiques situé dans une administration, d'une part, et les milieux de la recherche universitaire, d'autre part, et à évoquer certaines de ses conditions intellectuelles et administratives.

Le premier principe est qu'il est nécessaire pour le ministère de la Culture de recourir à des compétences extérieures, lorsque ces compétences n'existent pas au sein de ses services, ni même dans son département de socio-économie. Dans une administration, ce principe n'est pas aussi évident qu'il pourrait le paraitre $[\ldots]$.

Le deuxième principe est l'utilité de l'extériorité de la recherche scientifique par rapport à celle du ministère de la Culture. Cette utilité tient à ce que ces formes de recherche sont construites hors de toute dépendance hiérarchique ou d'autocensure inconsciente de la part des chercheurs. À titre d'exemple, la publication d'une recherche universitaire sur les débouchés des écoles nationales d'art a été dure à négocier avec le service administratif responsable parce que les conclusions de la recherche étaient en contradiction avec une réforme récente que ce service cherchait à faire passer dans les esprits. Plus profon- dément, l'extériorité de la recherche par rapport au ministère permet l'injection de problématiques nouvelles pour les stratégies du ministère. Pour évaluer le programme des études dans les conservatoires de musique, par exemple, ce n'est pas au ministère ni dans aucun conservatoire qu' on aurait pu entreprendre une analyse objective, mais à l'École des mines de Paris, dans son laboratoire de sociologie de l'innovation.

La troisième raison de favoriser un partenariat avec la recherche extérieure, c'est la création de compétences qui n'existent encore ni à la «Culture» ni au CNRS, ni à l'Université. Un bon exemple est donné par l'économie de la culture. Le Département des études disposait des crédits nécessaires pour traiter des problèmes économiques relatifs à la culture, mais il ne trouvait, il n'y a guère, qu'à peine dix personnes à qui les attribuer. Il fallait que se crée un milieu de recherche, que les universitaires s'intéressent au problème, accumulent et organisent un savoir. [...]

Pour qu'un partenariat soit fécond, il faut aussi que soient réunies certaines conditions éthiques. La première condition est que la finalité des travaux soit commune chez les deux partenaires. Cette finalité n'est autre que celle qu'Hubert Curien définissait déjà il y a vingt ans quand il était délégué à la recherche : «Notre finalité», disait-il, « est d'aider la décision dans le ministère chargé de la Culture ». Faire avancer la connaissance, oui, mais avec l'objectif d'éclairer l'action.

Mais pour que cette finalité soit respectée, il faut une problématique commune entre les deux partenaires, et que cette problématique soit au croisement d'une problématique de politique culturelle et d'une problématique de recherche. Les subventions de recherche du Département n'ont pas pour objet de mécéner la recherche culturelle dans l'infinie variété de ses facettes. Le critère des concours financiers apportés aux laboratoires est une problématique des politiques culturelles, et il faut que cette problématique culturelle 


\section{Quelques chercheurs... et partenaires}

Pierre Bourdieu, sociologue, a, au cours des années 1960, réalisé pour le compte du ministère des Affaires culturelles une enquête sur les publics des musées, source de l'ouvrage L'Amour de l'art. Les musées d'art européens et leurs publics (Paris, Minuit, 1966), coécrit avec Alain Darbel. Ses livres sur Les Héritiers. Les étudiants et la culture (Paris, Minuit, 1964; avec Jean-Claude Passeron) ou La Distinction, critique sociale du jugement (Paris, Minuit, 1979) ont largement contribué à faire connaître la sociologie de la culture.

Paul-Henry Chombart de Lauwe, sociologue, directeur d'études à l'École pratique des hautes études, a fait partie des experts sollicités dès le début des années 1960 par le ministère des Affaires culturelles. Spécialiste des loisirs et de l'éducation populaire, il a notamment publié La Culture et le pouvoir (Paris, Stock, 1975).

Michel Crozier, sociologue, a fait lui aussi partie des experts sollicités dès le début des années 1960 par le ministère des Affaires culturelles et s'est fait connaître par ses ouvrages, Le Phénomène bureaucratique (Paris, Le Seuil, 1965) et On ne change pas la société par décret (Paris, Grasset, 1979). En collaboration avec Erhard Friedberg, il est aussi l'auteur de l'ouvrage L'Acteur et le système (Paris, Le Seuil, 1977).

Erhard Friedberg, sociologue, a dirigé le Centre de sociologie des organisations jusqu'en 2007. Directeur du «master of public affairs" de l'Institut des études politiques de Paris («Sciences-Po»), il est à l'origine d'un «programme pour l'étude empirique, organisationnelle et sociale des nouvelles technologies de l'information et de la communication ». Coauteur, avec Michel Crozier, de L'Acteur et le système (Paris, Le Seuil, 1977), il a écrit, en collaboration avec Philippe Urfalino, Le Jeu du catalogue. Les contraintes de l'action culturelle dans les villes (Paris, La Documentation française, 1984).

Antoine Hennion, sociologue et musicologue, est directeur de recherches au Centre de sociologie de l'innovation de l'École des mines Paris Tech. Sa double formation l'a amené à s'intéresser à la sociologie de la musique, comme en témoignent plusieurs de ses ouvrages, dont Rock: de l'histoire au mythe (Paris, Anthropos, 1991; en collaboration avec Patrick Mignon), La Passion musicale. Une sociologie de la médiation (Paris, Métailié, 1993); Figures de l'amateur (Paris, La Découverte/Ministère de la Culture, 2000 ; avec S. Maisonneuve et $\mathrm{E}$. Gomart).

Pierre-Michel Menger, directeur de recherche au CNRS, directeur d'études à l'EHESS où il enseigne la sociologie du travail et celle des arts. II a notamment publié Le Paradoxe du musicien: le compositeur, le mélomane et l'État dans la société contemporaine (Paris, Flammarion, 1983) ; Portrait de l'artiste en travailleur. Métamorphoses du capitalisme (Paris, Le Seuil, 2002); Les Intermittents du spectacle (Paris, EHESS, 2005). Dernière publication : Le Travail créateur (Paris, Gallimard/Le Seuil/Éditions de l'EHESS, coll. « Hautes études », 2009).

Raymonde Moulin, sociologue, spécialiste des relations entre art et économie, a créé en 1983 le Centre de sociologie des arts (CSA) qu'elle a dirigé jusqu'en 1992 et qui est devenu en 2002 le Centre de sociologie du travail et des arts (CESTA). Elle a publié de nombreux ouvrages parmi lesquels L'Artiste, l'institution et le marché (Paris, Flammarion, 1992) et Sociologie de l'art (Paris, L'Harmattan, réédition 1999).

Philippe Urfalino, sociologue, directeur de recherche au CNRS, a pris depuis 2006 la direction du Centre de sociologie du travail et des arts (CESTA). II est notamment l'auteur de L'Invention de la politique culturelle (Paris, Hachette, 2004 - rééd.) et, avec Erhard Friedberg, de l'ouvrage Le Jeu du catalogue. Les contraintes de l'action culturelle dans les villes (Paris, La Documentation française, 1984). soit assimilée par les chercheurs qui, en retour, fournissent au ministère une problématique de recherche pour enrichir la problématique culturelle [...].

Au-delà de cette problématique commune, il convient que se développe un «esprit» commun qui est l'esprit contractuel [...] Pratiquement, en termes de voies et moyens, le partenariat idéal pourrait se traduire par la définition, en commun, de procédures de travail plus serrées et plus transparentes entre les deux partenaires, qui comporterait une précision plus élaborée au niveau du cahier des charges, des conditions strictes de suivi des études et, enfin, de l'évaluation des travaux [...].

Il existe enfin cinq conditions administratives au partenariat. Qui dit partenariat dit égalité des partenaires. Or, ce n'est pas le cas actuellement. Le partenaire du côté de la «Culture », c'est-à-dire le Département des études et de la prospective, est trop faible en hommes pour être un partenaire valable [...].

La deuxième condition administrative du partenariat, c'est que le CNRS et les universités facilitent les mises à disposition, pour une période limitée, de quelques chercheurs ou universitaires, de temps à autre [...].

La troisième condition, c'est que les contraintes bureaucratiques de l'administration de la recherche ne viennent pas s'ajouter aux habitudes administratives d'un ministère. Il y a une incompatibilité calamiteuse entre la recherche et le statut général de la fonction publique avec tout son appareil paritaire. La rigidité de la gestion des carrières, mais aussi des volumes budgétaires et du régime des vacations, interdit la rapidité de l'exécution et son efficacité. Rien n'est moins égalitaire que la recherche où tout est dans le talent, la passion et même dans le génie de l'invention. Ceuxci doivent être mis en mesure de se déployer vite et pleinement, sans esprit d'égalitarisme distributif. Quiconque a touché à la recherche connaît par cœur les développements auxquels conduit cette observation. On les censurera donc ici.

La quatrième condition [...] est le corollaire de la troisième : c'est de changer le statut du Département. On pourrait aisément concevoir que le Département devienne une fondation publique qui disposerait de l'autonomie de gestion, tout en restant financé par la puissance publique $[. .$.$] .$

La cinquième condition est le partenariat dans le partage des résultats de la recherche. [...]

Source : texte paru dans L'Art de la recherche. Essais en l'honneur de Raymonde Moulin, Paris, Ministère de la Culture et de la Francophonie/La Documentation française, 1994, p. 137-147 (textes réunis par Pierre-Michel Menger et Jean-Claude Passeron). 


\section{La naissance des politiques culturelles et les Rencontres d'Avignon (1964-1970)}

Nées de l'initiative de Jean Vilar et Michel Debeauvais, les Rencontres d'Avignon* ont réuni pendant sept étés successifs, dans l'environnement du célèbre festival, quelques dizaines de participants : responsables culturels, élus, experts, militants associatifs... Les extraits ci-dessous mêlent à certaines interventions d'Augustin Girard prononcées lors des Rencontres de 1966 quelques commentaires qui furent publiés en 1997. Des années 1960 à la fin du XXe siècle, une même ambition s'exprime : «Donner une dimension culturelle»aux «conditions d'existence de la population».

\section{INTERVENTION LORS DES RENCONTRES D'AVignon, 1966}

Certains m'ont dit: "Quoi ? Vous allez colloquer six jours du développement culturel régional, et vous ne savez même pas de quoi vous parlez? Dites-nous donc ce que c'est que la culture » [...] La culture, c'est ce qui se passe ici tous les soirs, et tous les après-midi au Verger pour des milliers de jeunes et de moins jeunes [...] Nous ne savons peut-être pas bien ce qui se passe au juste dans la tête des gens dont nous croisons le regard, mais nous savons fort bien qu'il s'y passe quelque chose.

Or, ce qui se passe ici tous les soirs, et tous les après-midi au Verger, était jusqu'il y a vingt ans, et à quelques exceptions près, le privilège des gens qui habitaient Paris. Ce que nous allons dire durant ces six jours, c'est comment ce privilège est en passe de devenir régulièrement et habituellement le partage de tous ceux qui habitent les régions de la France. Et voilà pourquoi nous parlons de développement culturel régional.

Mais d'où vient que les villes et les régions se mettent en mouvement? Il y a, comme toujours, plusieurs causes et qui ne sont pas toutes d'ordre culturel. Si je prends le conseiller municipal moyen, et que je cherche ce qui a d'abord éveillé sa conscience, je ne trouverai pas de problèmes culturels, mais bien plus des problèmes de loisirs des jeunes. Nous ne nous en souvenons peut-être déjà plus, mais c'est par une politique de prévention sociale qu'a commencé une politique de la jeunesse. Puis il y a eu des lois-programmes, des crédits, et l'on a découvert l'ampleur du problème. En même temps arrivaient au pouvoir - pouvoir local - des hommes d'une génération nouvelle, ceux qui avaient vingt ans à la Libération, qui ont gardé de cette époque une certaine idéologie, et pour qui notamment la gestion locale n'est plus la juxtaposition de problèmes politiques locaux, mais une affaire d'aménagement des conditions d'existence de

\section{Jean Vilar et les Rencontres d'Avignon}

"C'est au cours des années 1960 qu'est née la notion de politique de la culture en France, au niveau national comme au niveau local. Certes, la vision de Malraux ainsi que la dynamique de la planification ont alors fait avancer la réflexion sur les politiques culturelles et leur mise en route. " Ainsi s'exprime Augustin Girard, en 1997, dans sa présentation du livre sur les Rencontres d'Avignon.

Dans la Cité des papes comme au Théâtre national populaire, Jean Vilar (1912-1971) manifeste la même ambition : faciliter l'accès du public le plus large, "le boutiquier de Suresnes, le haut magistrat, l'ouvrier de Puteaux et l'agent de change, le facteur des pauvres et le professeur agrégé ", aux grands textes dramatiques d'hier et d'aujourd'hui. C'est dans cet esprit que, de 1964 à 1970, il organise parallèlement au Festival les « Rencontres d'Avignon ", lieu de débats où élus, artistes, délégués d'associations, universitaires, représentants du tout jeune ministère des Affaires culturelles... inventent librement les politiques culturelles à venir: "Culture et État» en 1964, "Culture et École» en 1965, "Culture et Région» en 1966, «Culture et Ville » de 1967 à 1970. « Notre intention », disait-il, « est de vous entraîner dans un commun complot " afin d'assurer au plus grand nombre " une égale répartition des biens de la culture". Mais, ajoutait-il, « ce qu'il faut [...] éviter à tout prix [...], ce sont les sophismes glorieux, les arguties grandioses, qui masquent l'indolence, le mensonge ou tout simplement l'erreur. Hors des tons solennels qui appartiennent au romanesque de l'illusion et du lyrisme, ce sont ici, en effet, des débats de petites assemblées qui doivent avoir lieu ".

la population et d'équipements collectifs. Or, ces hommes sont contraints de repenser les problèmes d'équipement en raison de la pression démographique. [...]

Or, pareillement, les villes savent qu'elles vont doubler leur population dans les vingt années qui viennent. Vingt ans, ce n'est pas long, cela fait 1945-1965. Et, en vingt ans, il faut construire autant de logements, d'écoles, d'hôpitaux et de théâtres qu'il y en a déjà dans ces villes. Les élus locaux qui se trouvent devant cette obligation - et la planification est dans ce domaine de l'équipement combien inéluctable - ne peuvent pas ne pas réfléchir. Impossible de faire de la 
gestion au jour le jour, ou même de quatre ans en quatre ans. Or, réfléchissant à vingt ans, ils ne peuvent pas ne pas compter avec les besoins nouveaux qu'entraînent 60 \% de bacheliers, une automobile par ménage, trente heures de télévision, et deux jours chômés par semaine, et le reste. Du coup, reparaît la vieille fonction : organiser les jeux du cirque, aménager les loisirs et leur donner une dimension culturelle. Car [...] les migrants n'iront dans les villes que s'ils y trouvent du plaisir. Voilà comment la planification conduit, de façon naturelle, vers le développement culturel régional $[\ldots]$.

\section{CONTRIBUTION À LA PUBLICATION DES RENCONTRES D’AVignON, 1997}

[...] On serait facilement tenté de faire d'un homme de théâtre pas comme les autres un personnage charismatique, une sorte de guide aux intuitions imbattables, prophétiques. Vilar, dans sa dignité simple et grande, n'avait rien d'un surdoué, encore moins d'un gourou, et pas même d'un intellectuel.

C'était avant tout un homme de métier, accompli comme un compagnon du Tour de France. Il avait l'allure de ces compagnons du Devoir, autant capables du chef-d'œuvre que du simple service d'hospitalité. Son honnêteté fraternelle était sans détour ni retour, droite et naturelle comme l'engagement d'un jeune de dixneuf ans dans la Résistance.

Ce sont ces réflexes quasi d'enfance qui en imposaient, que les passants appelaient sa solennité, alors que sa gravité vraie n'était que celle du clown de Rouault, aussitôt qu'il est sorti de scène. Il ne se résolvait qu'avec peine à prendre au sérieux ce qu'il lui advenait d'avoir à dire en dehors de son métier.

Tel apparut à certains d'entre nous celui qui les appela un à un, sans raison déclarée, à monter de bonne heure chaque matin trois étages de marches verticales jusqu'à une pièce carrée, toute de pierre blanche, éclairée par des meurtrières haut perchées près de poutres énormes. En bas, un rectangle de tréteaux nus évoquait la mythique «table ronde». Vilar occupait le fond, le regard perdu au-dessus des têtes, tandis qu'à son côté, assis un peu de travers, Michel Debeauvais parlait d'une voix douce, la tête penchée comme s'il interrogeait à la fois son voisin et la salle.

« Interrogeait »? Voilà le maître-mot lancé, commencement, principe et fin de ces « Rencontres ». Car il apparut vite que Vilar et Debeauvais n'avaient pas rassemblé des personnages armés de réponses toutes prêtes, mandatés par des groupes constitués, professionnels, institutionnels, syndicaux ou politiques afin de confronter leurs réponses entre elles, et terminer sur des motions habilement balancées, aussi rapidement oubliées que rédigées. Ils prirent toujours soin de répéter, de 1964 à 1970, à l'ouverture et à la clôture de chaque «Rencontre » qu'il s'agissait uniquement de poser correctement de bonnes questions, de « resserrer des problèmes ». En cela, ils étaient tacitement proches d'un Malraux qui déclarait aux députés que «la culture n'était pas là pour fournir les bonnes réponses, mais pour poser les bonnes questions", proches aussi des savants qui déclarent avec LéviStrauss que «le scientifique n'est pas celui qui fournit les réponses vraies, mais celui qui pose les vraies questions» $[\ldots]$.

\section{Rencontres d'idées? - Rencontres d'hommes}

[L'avancée] que je veux retenir pour demain - de ces commencements, de ces forces vivifiées à l'oxygène naissant, c'est le primat non pas des idées, mais le primat des hommes. Rencontres d'idées, certes. Mais rencontres d'hommes d'abord, autour d'un homme. C'est entre eux que se créa l'esprit des Rencontres, ces « débats de petite assemblée », comme les appelait Vilar avant même qu'ils ne commencent.

Quiconque promènera son scaphandre portatif dans les fonds bariolés de ces quatre cents pages sera étonné de redécouvrir l'état incroyable de fragilité économique et politique, de précarité conceptuelle de l'action culturelle publique au soir de la Quatrième République. L'audace des petits commandos malruciens, l'habileté de leurs successeurs, la rarissime conjonction des astres politiques et culturels sous les présidences Mitterrand ont fini par donner une telle abondance à l'offre culturelle publique que nous la croirions chaque été presque aussi naturelle que le réseau routier. Mais lisez entre les lignes des «actes » de quels moyens disposaient en 1960 les Dasté, les Gignoux, les Monnet, les Rétoré et autres Tréhard, et voyez le chemin parcouru.

Aujourd'hui - et pour demain - où l'environnement technologique, économique, éducatif et social de la culture se transforme à un rythme qui éclate enfin au visage de tous, nous disons que l'esprit de la «petite assemblée »n'est pas accessoire dans la vie du ministère, mais constitue une nécessité de première priorité. C'est seulement en attaquant les maux de la société dans ce qu'ils ont de plus profond qu'on pourra expliciter le rôle que la culture ne peut pas ne pas tenir. Et ce n'est pas avec des séminaires de «gestion» qu'on trouvera les bonnes solutions, et encore moins « les vraies questions » à placer au cœur de l'agenda gouvernemental.

\footnotetext{
Source: textes parus dans La Naissance des politiques culturelles et les Rencontres d'Avignon sous la présidence de Jean Vilar (1964-1970), présenté par Philippe Poirrier, Paris, La Documentation française, Ministère de la Culture et de la Communication, Comité d'histoire, coll. «Travaux et documents n 6 », 1997 (épuisé : consultable au Comité d'histoire).
} 


\section{Repères CHRONOLOGIQUeS \\ Augustin Girard (1926-2009)}

Agrégé de l'Université

1962-1965 Rapporteur du groupe «Action culturelle » du IVe Plan.

1963 Dans le cadre d'une coopération avec le Commissariat général du Plan, il crée une cellule d'études et de recherches au ministère des Affaires culturelles, qui deviendra le Service des études et recherches (SER) en 1968, puis Département des études et de la prospective (DEP) en 1986, enfin Département des études, de la prospective et des statistiques (DEPS) en 2004.

1966 Membre de la Délégation française à la Conférence générale de l'Unesco qui adopta la Déclaration des principes de la coopération culturelle internationale.

1968 Rapporteur de la commission «Sciences et culture " à la XVe conférence générale de l'Unesco.

1970 et 1972 Rapporteur général des conférences des ministres de la Culture à Venise et à Helsinki.

1970-1980 Directeur du programme «Développement culturel » du Conseil de l'Europe et membre de la délégation française aux conférences internationales des ministres de la Culture.
1971-1975 Rapporteur général adjoint de la Commission des affaires culturelles du Vle Plan.

1981 Rapporteur adjoint de la commission d'orientation sur les problèmes de l'audiovisuel présidée par Pierre Moinot.

1984-1988 Professeur à l'Institut d'études politiques de Paris et à I'Université Paris I.

1984-1989 Participe, à travers la réalisation d'études sur les politiques culturelles territoriales, à la réflexion puis à la création, en 1989, de l'Observatoire des politiques culturelles (OPC). II en devient le viceprésident fondateur.

1985 Membre du groupe de pilotage du programme d'évaluation des politiques culturelles en Europe mis en œuvre par le Conseil de l'Europe.

1993 Départ à la retraite. À la demande du ministre, il crée le Comité d'histoire et en est le président jusqu'en 2007.

\section{Études et recherches}

1962-1963 À la demande de Jacques Delors, création auprès du ministère des Affaires culturelles d'une cellule d'études - futur Services des études et recherches (SER) - chargée de pallier le manque de données précises chiffrées.

1964 Publication d'études sur les comptes culturels, les Maisons de la culture, la politique culturelle de villes, les publics... et de travaux à dimension internationale.

1968 Le SER est créé officiellement.

1969 Premier numéro du bulletin Développement culturel.

1973 Première enquête par sondage sur les pratiques culturelles (renouvelée en 1981, 1989, 1997 et 2008).

1974-1975 Premières enquêtes sur les dépenses culturelles de l'État et des collectivités.

1975-1984 Participation au programme statistique de l'Unesco. Une action concertée «DGRST/Fondation pour le développement culturel » conforte budgétairement le SER.

1977 Publication des premiers annuaires statistiques thématiques de la culture.

1980 Publication du premier annuaire statistique global « Des chiffres pour la culture».

1982 Multiplication par sept du budget du SER.

1984 Création de Circle (Centre d'information et de recherches sur la culture et la liaison documentaire en Europe) par le DEP et ses partenaires européens. Le DEP est chargé de réaliser Circular. Lettre de Circle/CIRCLE Newsletter, publication bi- ou trilingue de recherche et documentation sur les politiques culturelles. En 1998, Circular est réalisé sous la responsabilité du DEP en collaboration avec la fondation Boekman (membre néerlandais de Circle). Circular cesse de paraître en 2002.

1986 Le SER devient DEP. Informatisation du centre de documentation et création d'un thésaurus du domaine culturel. Création d'un conseil ministériel des études auprès du ministre de la Culture et de la Communication.
1989 Première édition de Chiffres clés, annuaire synthétique de chiffres sur la culture.

1993 Départ à la retraite d'Augustin Girard. Marc Nicolas lui succède, remplacé en 1997 par Paul Tolila, puis en 2005 par Philippe Chantepie, actuel chef du DEPS.

1995 Première réunion sur les statistiques culturelles européennes, organisée à l'initiative du DEP en vue d'étudier les conditions d'une coopération statistique européenne. Le DEP, collaborant avec l'Insee depuis 1972, devient service statistique ministériel (Ssm).

1997 Participation du DEP au groupe de travail sur les statistiques culturelles en Europe sous l'égide d'Eurostat service statistique international.

2005 Le DeP, devenu DePs en 2004, précédemment rattaché à la Direction de l'administration générale, est intégré à la Délégation au développement et aux affaires internationales (DDAI).

2006 Le DEPS, rattaché au Secrétariat général, refond son programme de moyen terme sur cinq axes d'analyse transversale: dynamiques des activités, de l'emploi et du travail ; évolution des pratiques, des publics et des consommations; modes de transmission et de légitimation; organisation de la création, de la production, de la diffusion et des marchés; analyse des politiques, interventions publiques, régulations. Eurostat lui confie la réalisation de Cultural Statistics, premier ouvrage sur les statistiques culturelles européennes harmonisées (27 Etats membres).

2007 Réorganisation et dématérialisation des publications: "culture chiffres", "culture études", "culture prospective» et "culture méthodes".

2009-2010 Le DEPS réalise un exercice de prospective sur la politique culturelle en 2030. II appuie la création d'un Groupement d'intérêt scientifique (GIs) « Médias et culture numériques », associant les disciplines sociologique, économique, juridique, etc.

\section{L'invention de la prospective culturelle. Textes choisis d'Augustin Girard \\ a été réalisé en collaboration par le DePs et le Comité d'histoire.}

Recherche et choix des textes: Olivier Donnat (DEPS), David Fouqueray, Geneviève Gentil et Katia Svirchevsky (Comité d'histoire).

Coordination éditoriale, sélection des extraits et secrétariat de rédaction : Jacqueline Boucherat et Michel Kneubühler.

Tous les articles présentés dans ce numéro sont disponibles in extenso sur le site du Comité d'histoire:

http://www.culture.gouv.fr/culture/comite-histoire.htm

Tous les documents publiés par le DEPs sont téléchargeables sur http://www.culture.gouv.fr/deps 